\title{
Caracterização geológica, petrográfica e geoquímica do Trondhjemito Mogno e Tonalito Mariazinha, Terreno Granito-Greenstone mesoarqueano de Rio Maria, SE do Pará
}

\author{
Fabriciana Vieira Guimarães ${ }^{1,2}$, Roberto Dall'Agnol ${ }^{1,3}$, \\ José de Arimatéia Costa de Almeida ${ }^{1,2}$ \& Marcelo Augusto de Oliveira ${ }^{1,2}$
}

\begin{abstract}
Resumo O Trondhjemito Mogno, uma das mais expressivas associações TTG do Terreno Granito-Greenstone de Rio Maria (TGGRM), tida como representativa da segunda geração de TTGs daquele terreno, apresenta, em sua principal área de ocorrência, diferenças estruturais, petrográficas, geoquímicas e geocronológicas que levaram à sua separação em duas associações distintas. A designação de Trondhjemito Mogno foi mantida para a associação dominante, com padrão estrutural NW-SE a EW, distribuída nos domínios leste e oeste da área. A nova associação identificada na porção centro-oeste da área mapeada, com foliação dominante NE-SW a N-S foi denominada de Tonalito Mariazinha. Reduziu-se, assim, à área de ocorrência do Trondhjemito Mogno e definiu-se nova unidade estratigráfica na região. Dados geocronológicos inéditos revelam que o Trondhjemito Mogno e o Tonalito Mariazinha possuem idades distintas e não fazem parte da segunda geração de TTGs do TGGRM. As duas associações estudadas são constituídas por epidoto-biotita tonalitos e trondhjemitos, os quais pertencem ao grupo de TTG com alto $\mathrm{Al}_{2} \mathrm{O}_{3}$ e possuem características geoquímicas compatíveis com as dos típicos granitóides arqueanos da série trondhjemítica. Comparações com TTGs da região de Xinguara mostram que o Trondhjemito Mogno possui características geoquímicas transicionais entre o Complexo Tonalítico Caracol e o Trondhjemito Água Fria, enquanto que o Tonalito Mariazinha se assemelha com o Complexo Tonalítico Caracol. Os estudos sobre o Trondhjemito Mogno e granitóides arqueanos associados demonstram que as associações TTG do TGGRM são mais diversificadas do que era admitido e contribuíram significativamente para sua melhor compreensão, reduzindo expressivamente as ocorrências da segunda geração de TTGs naquele terreno e levando à identificação de nova associação TTG.
\end{abstract}

Palavras-Chaves: Trondhjemito, Tonalito, TTG, Arqueano, Terreno Granito-Greenstone de Rio Maria.

\begin{abstract}
Geological, petrographical and geochemical characterization of Mogno Trondhjemite and Mariazinha Tonalite, mesoarchean rio Maria granite-greenstone terrane, southeastern of Pará. The Mogno Trondhjemite is one of the largest TTG units of the Rio Maria Granite-Greenstone Terrane (RMGGT). It was considered as representative of a second generation of Archean TTG in that terrane. However, field, petrographical, geochemical, and geochronological studies demonstrate the existence of two distinct TTG units in its main area of occurrence. For the dominant TTG unit, showing NW-SE to EW foliation and distributed in the eastern and western domains of the mapped area, the term Mogno Trondhjemite was maintained. The new TTG unit, which occurs in the center-western domain and displays a NE-SW to NS dominant trend, is named as Mariazinha Tonalite. Hence, the original area of occurrence of the Mogno Trondhjemite was significantly reduced. Moreover, $\mathrm{Pb}-\mathrm{Pb}$ zircon ages indicate that the Mogno Trondhjemite and the Mariazinha Tonalite are neither coeval, nor related to the second generation of TTGs of the RMGGT. The two TTG studied units are composed of epidote-biotite tonalites and trondhjemites of the high $\mathrm{Al}_{2} \mathrm{O}_{3}$ type, with geochemical characteristics similar to those of the typical Archean TTG granitoids. Compared with the Archean TTG units of the Xinguara region, the Mogno Trondhjemite geochemical characteristics are transitional between those of the Caracol Tonalitic Complex and the Água Fria Trondhjemite, while those of the Mariazinha Tonalite approaches those of the Caracol Tonalitic Complex. The studies undertaken in the Mogno Trondhjemite and associated Archean granitoids demonstrated that the TTG series of the RMGGT are more diversified and complex than previously admitted. The domain of the second Archean generation of TTG of the RMGGT was drastically reduced and a new Archean TTG association, the Mariazinha Tonalite, was identified and characterized.
\end{abstract}

Keywords: Trondhjemite, Tonalite, TTG, Archean, Rio Maria Granite-Greenstone Terrane, Amazonian craton.

1 - Universidade Federal do Pará (UFPA), Instituto de Geociências (IG), Grupo de Pesquisa Petrologia de Granitóides (GPPG), Belém (PA), Brasil.

2 - Programa de Pós-Graduação em Geologia e Geoquímica (PPGG), IG, UFPA, Belém (PA), Brasil. E-mail: fabricia@ufpa.br, ari@ufpa.

br, mao@ufpa.br

3 - UFPA, Instituto de Geociências (IG). E-mail: robdal@ufpa.br 
INTRODUÇÃOO O magmatismo arqueano do Terreno Granito-Greenstone de Rio Maria (TGGRM), localizado no sudeste do Estado do Pará (Fig. 1), possui idades variando de 2,98 a $2,86 \mathrm{Ga}$ e é formado por greenstone belts e associações granitóides, entre as quais se destacam suítes tonalítica-trondhjemítica-granodioríticas (TTG; Huhn et al. 1988, Santos \& Pena Filho 2000, Althoff et al. 2000, Souza et al. 2001, Leite et al. 2004, Dall'Agnol et al. 2006, Almeida et al. 2008, Vasquez et al. 2008).

Um dos principais corpos correlacionados ao magmatismo TTG do TGGRM é o Trondhjemito Mogno, descrito por Cordeiro \& Saueressig (1980), Huhn et al. (1988) e DOCEGEO (1988), para o qual foi obtida idade de ca. 2,87 Ga (U-Pb em titanita; Pimentel \& Machado 1994). Esta datação geocronológica não fornece total segurança quanto à idade de cristalização da unidade, mas evidências de campo, como a presença de xenólitos máficos englobados pelos trondhjemitos, interpretadas como indicativas de que seria intrusivo nos greenstone belts (Huhn et al. 1988), somadas à idade mencionada, posicionaram estratigráficamente o Trondhjemito Mogno (Fig. 1), posição esta em geral mantida em trabalhos subseqüentes (Souza 1994, Althoff et al. 2000, Souza et al. 2001, Leite et al. 2004, Dall'Agnol et al. 2006, Vasquez et al. 2008). Embora apresente uma ampla distribuição areal no TGGRM, esse TTG foi pouco estudado, o que implica necessidade da realização de estudos mais detalhados sobre o mesmo.

O presente trabalho visava originalmente aprimorar a caracterização geológica, petrográfica, e geoquímica da porção leste da principal área de ocorrência do Trondhjemito Mogno e melhor entender sua evolução. $\mathrm{O}$ avanço da pesquisa culminou com a identificação, na área mapeada, de duas associações TTG, aqui definidas e caracterizadas. Os resultados alcançados devem permitir avanços na interpretação da evolução do TGGRM e contribuir para a compreensão do ambiente tectônico de formação dos TTGs, ainda alvo de controvérsias (Martin 1994, Condie 2005, Halla et al. 2009, Almeida 2010).

CONTEXTO GEOLÓGICO REGIONAL O TGGRM está localizado nos domínios da Província Amazônia Central (Tassinari \& Macambira 2004) ou Carajás (Santos 2003) no sudeste do Cráton Amazônico. Apresenta como unidades mais antigas o Supergrupo Andorinhas, constituído por greenstone belts, com idades que variam de 2,98 a 2,90 Ga (Macambira 1992, Pimentel \& Machado 1994) e corpos plutônicos da série TTG originados entre 2,98 e 2,92 Ga, englobados no Tonalito Arco Verde ( idades U/Pb em zircão variáveis entre 2,98 e 2,94 Ga; Macambira 1992, Ma-
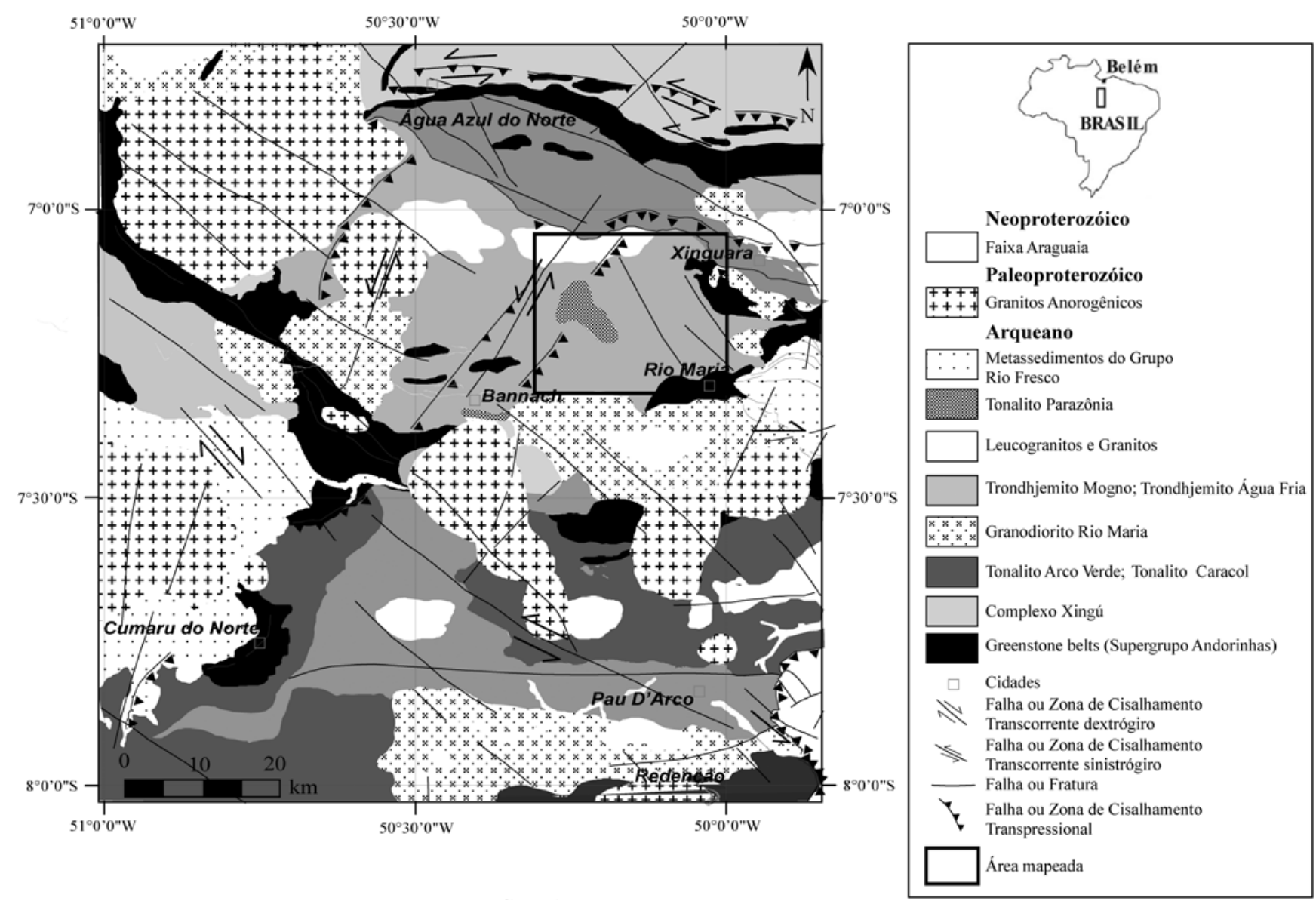

Figura 1 - Mapa geológico do Terreno Granito-Greenstone de Rio Maria (Almeida et al. 2008, modificado a partir de Huhn et al. 1988, Souza 1994, Santos \& Pena Filho 2000, Althoff et al. 2000, Leite 2001). 
cambira \& Lafon 1995, Rolando \& Macambira, 2002, 2003, Almeida et al. 2008), e no Complexo Tonalítico Caracol (2,95 a 2,92 Ga; Leite et al. 2004). Althoff et al. (2000) sugerem, ainda, a existência de uma geração de leucogranitos com idade de $\sim 2,93 \mathrm{Ga}$ representada pelo Granito Guarantã.

Em 2,87-2,86 Ga, novo evento magmático gerou diferentes granitóides: 1) TTGs representados pelo Trondhjemito Água Fria e, hipoteticamente, pelo Trondhjemito Mogno (Huhn et al. 1988, Souza 1994, Leite et al. 2004); 2) granitóides sanukitóides do tipo Granodiorito Rio Maria (Medeiros \& Dall'Agnol 1988, Souza 1994, Althoff et al. 2000, Leite 2001, Oliveira et al. 2006, 2009); 3 ) leucogranitos de afinidade cálcicoalcalina, tipo Mata Surrão (Duarte 1992) e Xinguara (Leite et al. 1999, 2004). Foi individualizado, ainda, o Tonalito Parazônia (Huhn et al. 1988), que forneceu uma idade de $2858 \mathrm{Ma}$ (U-Pb em titanita; Pimentel \& Machado 1994) e seria intrusivo no Trondhjemito Mogno, relação esta não confirmada por Souza (1994). Após a geração destes granitóides, formaram-se as rochas sedimentares do Grupo Rio Fresco.

Em torno de 1,88 Ga, a região foi palco de magmatismo granítico anorogênico (Dall'Agnol et al. 2005, Oliveira 2006, Almeida et al. 2006), representado pelos corpos graníticos da Suíte Jamon e por diques félsicos a máficos contemporâneos (Silva Jr. et al. 1999).

GRANITÓIDES TTG DO TGGRM As associações TTG têm vastas exposições no TGGRM e foram estudadas nas áreas de Xinguara (Leite et al. 2004), Marajoara/ Pau D'Arco (Althoff 1996, Althoff et al. 2000, Almeida et al. 2008), e leste de Bannach. Esses granitóides em geral ocorrem como batólitos, porém stocks também foram identificados (Leite 2001). Tais estudos indicaram a existência no TGGRM de duas gerações de associações TTG, distinguidas por suas idades (Tab. 1).
Participavam da primeira geração de associações TTG, apenas o Tonalito Arco Verde (Macambira \& Lancelot 1996, Althoff et al. 2000, Almeida et al. 2008) e o Complexo Tonalítico Caracol (Leite 2001, Leite et al. 2004), os quais eram, até a realização dos estudos de Almeida (2010), os granitóides mais antigos datados no TGGRM. Eles são cortados pelo Granodiorito Rio Maria, Trondhjemito Água Fria, leucogranitos cálcico-alcalinos e granitos da Suíte Jamon (Dall'Agnol et al. 2006).

Segundo Althoff (1996) e Althoff et al. (2000), o Tonalito Arco Verde exibe uma foliação com direção de 100 a $120^{\circ} \mathrm{Az}$, definida pela alternância de bandas trondhjemíticas e tonalíticas e por enclaves máficos achatados. Em zonas fortemente deformadas, o bandamento composicional está associado com xistosidade subvertical. Lineações mineral e de estiramento, quando presentes, são sempre subhorizontais e marcadas pelo alongamento dos cristais de quartzo, os quais mostram microestruturas que sugerem recristalização sob média a alta temperatura. Em domínios localizados de baixa deformação, as feições magmáticas estão parcialmente preservadas.

As rochas do Complexo Tonalítico Caracol têm bandamento composicional muito regular, definido por bandas de plagioclásio + quartzo, alternadas com bandas enriquecidas em biotita e minerais acessórios (Leite 2001). Estão muito deformadas e são raras as amostras com textura magmática preservada. No seu principal domínio, a sul de Xinguara, apresenta direção NW-SE e mergulhos de $40^{\circ}$ a subverticais.

As rochas dos tonalitos em questão são bastante similares, exibem coloração cinza clara a escura e textura fanerítica, equigranular ou heterogranular, com granulação média. Têm biotita como principal fase ferromagnesiana e, dentre os minerais acessórios, destacam-se zircão, titanita, opacos, allanita, epidoto e apatita.

Quanto às características geoquímicas, o To-

Tabela 1- Síntese dos dados geocronológicos de associações TTG do Terreno Granito-Greenstone de Rio Maria.

\begin{tabular}{|c|c|c|c|c|}
\hline $\begin{array}{c}\text { Unidades } \\
\text { Estratigráficas }\end{array}$ & Tipo de Rocha & Método & $\begin{array}{c}\text { Material } \\
\text { Analisado }\end{array}$ & Idade/Referência \\
\hline Tonalito Parazônia & Granitóide & $\mathrm{U}-\mathrm{Pb}$ & Titanita & $2858 \mathrm{Ma}(2)$ \\
\hline Trondhjemito Água Fria & Trondhjemito & $\mathrm{Pb}-\mathrm{Pb}$ & Zircão & $2864 \pm 21 \mathrm{Ma}(4)$ \\
\hline $\begin{array}{l}\text { Tonalito Mariazinha } \\
\text { Trondhjemito Mogno }\end{array}$ & $\begin{array}{c}\text { Tonalito } \\
\text { Granitóide } \\
\text { Trondhjemito } \\
\text { Trondhjemito } \\
\text { Trondhjemito } \\
\end{array}$ & $\begin{array}{l}\mathrm{Pb}-\mathrm{Pb} \\
\mathrm{U}-\mathrm{Pb} \\
\mathrm{Pb}-\mathrm{Pb} \\
\mathrm{Pb}-\mathrm{Pb} \\
\mathrm{Pb}-\mathrm{Pb}\end{array}$ & $\begin{array}{l}\text { Zircão } \\
\text { Titanita } \\
\text { Zircão } \\
\text { Zircão } \\
\text { Zircão } \\
\end{array}$ & $\begin{array}{c}2925 \pm 4 \mathrm{Ma}(8) \\
2871 \pm ? \mathrm{Ma}(2) \\
2959 \pm 5 \mathrm{Ma}(8) \\
2900 \pm 21 \mathrm{Ma}(4) \\
2857 \pm 13 \mathrm{Ma}(4)\end{array}$ \\
\hline Complexo Tonalítico Caracol & $\begin{array}{l}\text { Tonalito } \\
\text { Tonalito } \\
\text { Tonalito }\end{array}$ & $\begin{array}{l}\mathrm{Pb}-\mathrm{Pb} \\
\mathrm{Pb}-\mathrm{Pb} \\
\mathrm{Pb}-\mathrm{Pb}\end{array}$ & $\begin{array}{l}\text { Zircão } \\
\text { Zircão } \\
\text { Zircão }\end{array}$ & $\begin{array}{l}2948 \pm 5 \mathrm{Ma}(5) \\
2936 \pm 3 \mathrm{Ma}(5) \\
2924 \pm 2 \mathrm{Ma}(5) \\
\end{array}$ \\
\hline Tonalito Arco Verde & Tonalito & $\begin{array}{l}\mathrm{U}-\mathrm{Pb} \\
\mathrm{Pb}-\mathrm{Pb} \\
\mathrm{Pb}-\mathrm{Pb} \\
\mathrm{Pb}-\mathrm{Pb}\end{array}$ & $\begin{array}{l}\text { Zircão } \\
\text { Zircão } \\
\text { Zircão } \\
\text { Zircão }\end{array}$ & $\begin{array}{c}2957+25 /-21 \mathrm{Ma}(1) \\
2948 \pm 7 \mathrm{Ma}(3) \\
2981 \pm 8 \mathrm{Ma}(6) \\
2936 \pm 4 \mathrm{Ma}(7)\end{array}$ \\
\hline
\end{tabular}

Fonte dos dados: (1) Macambira (1992); (2) Pimentel \& Machado (1994); (3) Rolando \& Macambira (2002); (4) Macambira et al. (2000); (5) Leite et al. (2004); (6) Rolando \& Macambira (2003); (7) Almeida et al. (2008); (8) Almeida (2010) 
nalito Arco Verde é uma típica suíte TTG, similar aos trondhjemitos com baixo $\mathrm{Al}_{2} \mathrm{O}_{3}$, com termos mais evoluídos ricos em $\mathrm{Na}_{2} \mathrm{O}$, distinto do que ocorre em séries cálcico-alcalinas (Âlthoff 1996, Althoff et al. 2000). Os padrões de elementos terras raras mostram anomalia de $\mathrm{Eu}$ ausente ou discreta e acentuado fracionamento dos ETRP (Althoff et al. 2000). O Complexo Tonalítico Caracol é um TTG com alto $\mathrm{Al}_{2} \mathrm{O}_{3}$ e foi dividido geoquimicamente em dois subgrupos: o dominante é similar em termos do comportamento dos ETR aos tonalitos Arco Verde e o subordinado apresenta razões $(\mathrm{La} /$ $\mathrm{Yb}$ )n comparativamente baixas e significativa anomalia negativa de európio (Leite 2001). O magma gerador das rochas com altas razões $(\mathrm{La} / \mathrm{Yb}) n$ seria oriundo da fusão de metabasaltos não enriquecidos, previamente transformados em granada-anfibolito, ao passo que o segundo subgrupo seria derivado da fusão de rochas desprovidas de granada. Tais metabasaltos poderiam provavelmente corresponder aos do greenstone belt de Identidade ou a rochas geoquimicamente similares (Leite 2001). Segundo Althoff et al. (2000), o magma gerador do Tonalito Arco Verde também derivaria de fusão parcial de granada-anfibolito.

A segunda geração de TTGs, designada informalmente de TTG jovens (Dall'Agnol et al. 2006), deve ser revista em função dos resultados do estudo do Trodhjemito Mogno (Guimarães 2009, Almeida 2010). Um pluton de composição trondhjemítica, aflorante a leste da cidade de Bannach, foi correlacionado tentativamente ao Trondhjemito Mogno (2009), tendo sido confirmada esta interpretação por datações geocronológicas (Almeida 2010).

No domínio de ocorrência do Trondhjemito Mogno fora individualizado anteriormente um corpo de rochas TTG, denominado de Tonalito Parazônia (Hunh et al. 1988, Santos \& Pena Filho 2000; cf. Tab. 1). Esta unidade era muito pobremente caracterizada, tendo sido estudada em maior detalhe (Guimarães 2009) e datada por métodos mais precisos (Almeida, 2010). Os novos dados indicam sua correlação com as suítes sanukitóides do TGGRM (Oliveira et al. 2009) e não com as associações TTG (Guimarães 2009).

As informações mais detalhadas sobre a segunda geração de TTG provêm dos estudos do Trondhjemito Âgua Fria (Leite 2001, Leite et al. 2004). Relações de campo mostram que este é intrusivo nos greenstones belts, no Complexo Tonalítico Caracol, em granitóides ricos em $\mathrm{MgO}$ e contemporâneo aos leucogranitos potássicos do tipo Xinguara. O Trondhjemito Água Fria distingue-se do Complexo Tonalítico Caracol por apresentar deformação menos intensa, bandas menos espessas e mais regulares e maior número de enclaves, entre os quais são comuns enclaves métricos alongados do referido complexo. A principal estrutura do Trondhjemito Água Fria é um bandamento composicional de orientação preferencial NW-SE a WNW-ESE e mergulhos verticais, e, mais localmente, direção N-S e mergulho subvertical (Leite 2001). Nestes locais, ocorrem veios do Granito Xinguara paralelos ao bandamento do trondhjemito, mas sem bordas de resfriamento, sugestivo que ambas as rochas cristalizaram simultaneamente.

O stock de Bannach é alongado segundo NNW

(Fig. 1) e é constituído por rochas tonalítico-trondhjemíticas, similares ao Trondhjemito Mogno, que apresentam textura equigranular média ou, localmente, grossa ou fina.

Os supostos TTG jovens revelam caráter trondhjemítico dominante, com termos tonalíticos e granodioríticos subordinados. Em linhas gerais, são similares petrográfica e geoquimicamente aos TTG antigos, se diferenciando fundamentalmente pelo conteúdo de minerais máficos e pela presença significativa de álcalifeldspato nos granodioritos (Leite 2001). Mostram enriquecimento gradual em $\mathrm{K}$ nos termos mais ricos em sílica, o que reflete a formação tardia de termos granodioríticos (Nockolds \& Allen 1953, Barker \& Arth 1976). Os magmas que originaram os trondhjemitos Mogno e Água Fria foram gerados provavelmente por processos semelhantes aos que formaram os tonalitos Arco Verde e Caracol.

\section{CARACTERIZAÇÃO DAS ASSOCIAÇÕES TTG DO DOMÍNIO LESTE DE OCORRÊNCIA DO TRONDHJEMITO MOGNO}

Revisão dos Dados Geocronológicos do Trondhjemito Mogno Em mapeamento na escala 1:250.000, executado pela CPRM, foi identificada no Trondhjemito Mogno uma trama planar de direção NE-SW, discordante da estruturação regional arqueana, o que levou Neves e Vale (1999) e Santos e Pena Filho (2000) a considerarem-no como embasamento do Terreno Granito-Greenstone. Esta interpretação contrasta com a dominante na literatura que considera o Trondhjemito Mogno como formado há 2,87 Ma e o associa aos TTGs jovens do TGGRM (Tab. 1; ver Dall'Agnol et al. 2006, Vasquez et al. 2008, e referências lá contidas). Portanto, permanecem dúvidas quanto ao posicionamento estratigráfico do Trondhjemito Mogno, devido à indefinição de sua idade de cristalização.

Datação (Tab. 1) pelo método U-Pb em titanita indicou idade de 2871 \pm ? Ma (Pimentel e Machado 1994), que tem sido interpretada como idade de cristalização deste granitóide, embora possa corresponder à sua idade mínima de cristalização. $\mathrm{O}$ fato de esta última idade ter sido assumida como idade de cristalização fez com que o Trondhjemito Mogno fosse vinculado à segunda geração de granitóides TTG do TGGRM. Isto foi até certo ponto reforçado pelas idades $\mathrm{Pb}-\mathrm{Pb}$ em zircão obtidas posteriormente na porção sudeste $(2900 \pm 21 \mathrm{Ma})$ e centro-oeste $(2857 \pm 13 \mathrm{Ma})$ da área de exposição do Trondhjemito Mogno (Ver Tab. 1; Macambira et al. 2000).

Para definir a idade desta unidade, foram efetuados novos estudos geocronológicos (Almeida 2010, Almeida et al. submetido). Dentre as amostras datadas, uma de trondhjemito, coletada na porção leste da área em estudo, apresentou idade de $2959 \pm 5 \mathrm{Ma}$, enquanto outra de tonalito, ocorrente na porção oeste, forneceu idade de $2925 \pm 2$ (Tab. 1).

Esses novos dados geocronológicos, somados aos dados estruturais, petrográficos e geoquímicos, indicaram que o Trondhjemito Mogno não era uma unidade 
homogênea e levaram à separação na área mapeada de duas associações TTG. Para a porção leste da área mapeada foi mantida a denominação de Trondhjemito Mogno, enquanto que a associação TTG aflorante a oeste foi denominada de Tonalito Mariazinha (Fig. 2). Além disso, as idades obtidas por Almeida (2010) demonstraram que não se justificava a correlação do Trondhjemito Mogno com a segunda geração de TTGs do TGGRM.

Geologia Foi feito mapeamento na escala 1:100.000 do domínio leste da principal área de exposição do Trondhjemito Mogno, que abrange também a área de ocorrência do Tonalito Parazônia.

A área é caracterizada por um relevo planeplanizado, o que dificulta a definição das relações de contato entre os diversos litotipos. As feições estruturais evidenciaram a presença de variações expressivas na direção das foliações, que estão ora orientadas segundo as direções E-W a NW-SE, coincidentes com as dominantes no TGGRM, ora segundo NE-SW a N-S. Este último trend é francamente dominante no domínio oeste de ocorrência da associação TTG (Fig. 2), que neste trabalho foi denominada de Tonalito Mariazinha.

Foram distinguidos dois domínios na área originalmente atribuída ao Trondhjemito Mogno, ocorrências de dois outros tipos de granitóides e uma exposição localizada de greenstone belts (Fig. 2). Em parte da admitida área de ocorrência do Tonalito Parazônia, foram identificados quartzo-dioritos, afins das associações sanukitóides do TGGRM (Oliveira et al. 2006,
2009). Também foram mapeados três stocks formados essencialmente por biotita-granodiorito, inteiramente distinto dos TTGs e das rochas sanukitóides (Fig. 2). O presente trabalho se atém às associações TTG, sem abordagem mais profunda dos demais granitóides. Cabe destacar que o mapeamento realizado não abrangeu as porções NE e NW da área (Fig. 2), porém a primeira foi estudada em detalhe (Souza 1994, Leite 2001).

GREENSTONE BELTS (SUPERGRUPO ANDORINHAS) Além das ocorrências da Faixa Identidade (Souza 1994, Souza et al. 1997), também ocorrem afloramentos isolados de rochas vulcânicas com lavas em almofada na porção sudoeste da área (Fig. 2). Ademais, enclaves máficos alongados nos TTGs foram interpretados como derivados dos greenstone belts.

TRONDHJEMITO MOGNO Seus afloramentos são na forma de lajedos ou matacões e, geralmente, se apresenta intensamente deformado e fortemente bandado. $\mathrm{O}$ bandamento e a foliação apresentam direção NW-SE a E-W, sendo a foliação marcada pelos minerais máficos e cristais de quartzo e feldspatos alongados. É cortado por veios de leucogranitos e vênulas de epidoto. As relações de contato com as demais unidades não são claras.

TONALITO MARIAZINHA Seus afloramentos mais comuns são em lajedos e, em geral, apresenta-se moderadamente deformado, com bandamento composicional caracterizado pela alternância de níveis ricos em quartzo e

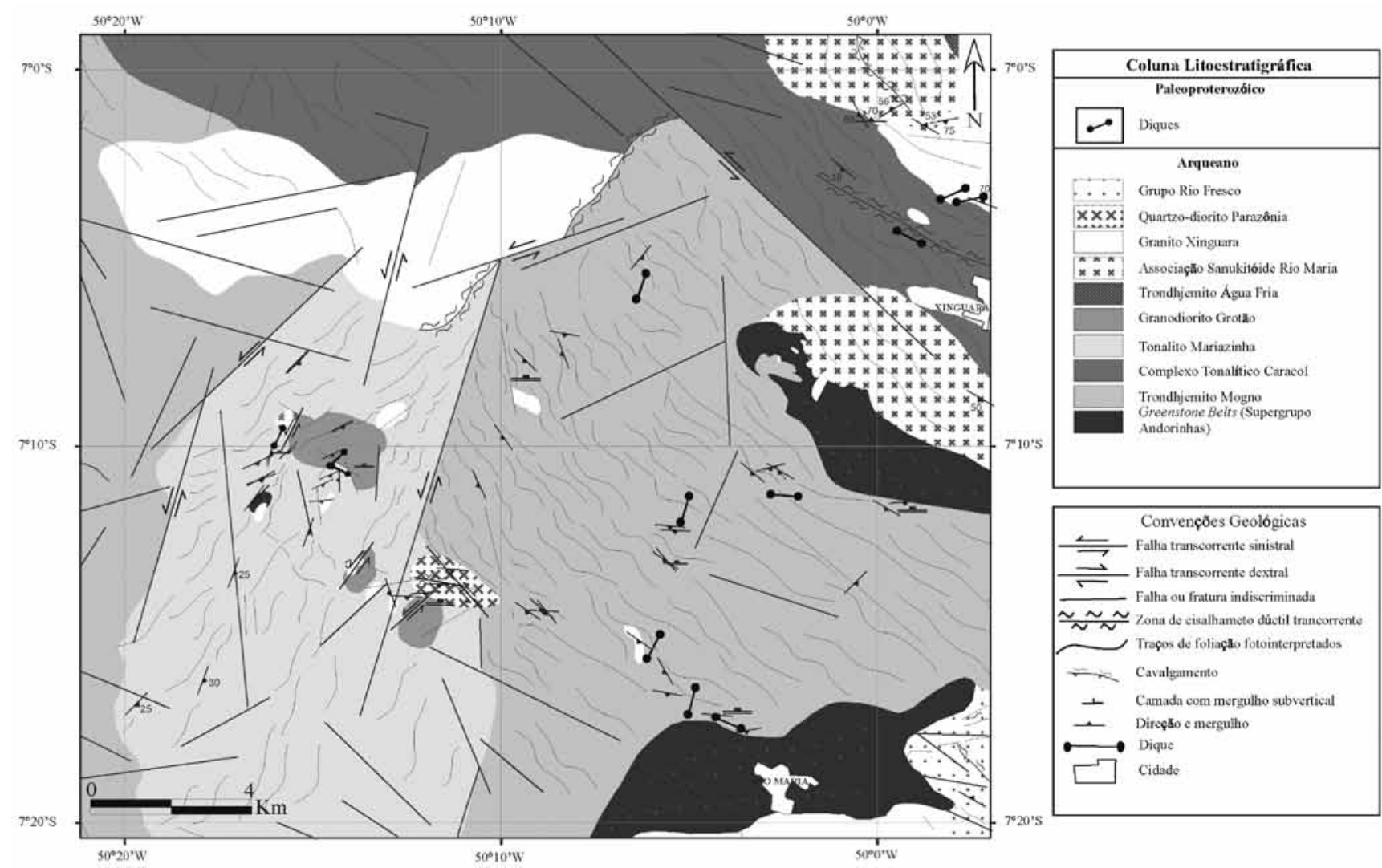

Figura 2 - Mapa geológico da área estudada. 
plagioclásio, estirados e alongados, e níveis mais enriquecidos em biotita. No geral, a foliação apresenta direção dominante NE-SW a N-S. Esta associação TTG é cortada por veios de leucogranitos concordantes com a direção da foliação e, localmente, engloba enclaves máficos.

GRANODIORITO GROTÃO Ocorre de forma localizada nas porções oeste e sudoeste (Fig. 2), em extensos afloramentos homogêneos. Suas rochas têm aspecto maciço, englobam enclaves de rochas tonalíticas ou trondhjemíticas, deduzindo-se que sejam intrusivas no Tonalito Mariazinha, e são cortadas por veios de leucogranitos.

QUARTZO-DIORITO PARAZÔNIA Forma um pequeno stock de pouca expressão na topografia na porção sudoeste da área (Fig. 2), aflorando em blocos e matacões, por vezes com área de exposição expressiva (Fazenda Parazônia). Embora as relações de campo não sejam inteiramente conclusivas, admite-se que seja intrusivo no Tonalito Mariazinha, ao passo que suas relações com as demais unidades não foram observadas. Este corpo, embora de menor área, corresponde ao denominado anteriormente de Tonalito Parazônia.

LEUCOGRANITOS ARQUEANOS Granitos e leucogranitos variados estão presentes de forma localizada em toda a área mapeada, formando pequenos corpos, geralmente sem representatividade na escala de mapeamento adotada, ou veios que cortam a maioria dos litotipos presentes. São correlacionados ao Granito Xinguara (Fig. 2).

SUÍTE JAMON Diques de composição máfica e félsica cortam as unidades arqueanas e foram correlacionados aos diques paleoproterozóicos da Suíte Jamon (Dall'Agnol et al. 2005).

\section{Petrografia}

COMPOSIÇÕES MODAIS E CLASSIFICAÇÃO O Trondhjemito Mogno e o Tonalito Mariazinha apresentam características petrográficas semelhantes, com variações limitadas nas percentagens de seus minerais (Tab. 2). Foram realizadas análises modais em vinte $\mathrm{e}$ uma amostras das associações TTG, e os resultados lançados em diagramas Q-A-P e Q-A+P-M' (Fig. 3), nos quais se situam no campo de tonalitos e trondhjemitos. Conforme Le Maitre (2002), as rochas trondhjemíticas apresentam conteúdo de minerais máficos inferior a $10 \%$ (média de $7 \%$ ), enquanto os tonalitos superam esse valor (média de 13,5\%). Ambas as variedades contêm mais de $48,5 \%$ de plagioclásio, cerca de 30 a $40 \%$ de quartzo modal, e o álcali-feldspato é acessório (Tab. 2). A biotita e o epidoto magmático são os principais minerais ferromagnesianos, sendo notável a

Tabela 2 - Composições modais ${ }^{(1)}$ de amostras das associações TTG estudadas.

\begin{tabular}{|c|c|c|c|c|c|c|c|c|c|c|c|c|c|c|c|c|c|c|c|c|c|}
\hline \multirow{2}{*}{$\begin{array}{l}\text { Unidades } \\
\text { Litologia }\end{array}$} & \multirow[b]{2}{*}{\begin{tabular}{|c|} 
Epidoto \\
- Biotita \\
Tonalito
\end{tabular}} & \multicolumn{11}{|c|}{ Trondhjemito Mogno } & \multicolumn{9}{|c|}{ Tonalito Mariazinha } \\
\hline & & & & & & $\begin{array}{l}\text { Epido } \\
\text { Tror }\end{array}$ & $\begin{array}{l}\text { oto - B } \\
\text { ndhjen }\end{array}$ & $\begin{array}{l}\text { iotita } \\
\text { nito }\end{array}$ & & & & & & Epido & $\begin{array}{l}\text { oto }-\mathrm{B} \\
\text { Tonalit }\end{array}$ & $\begin{array}{l}\text { Biotita } \\
\text { to }\end{array}$ & & & $\begin{array}{l}\text { pidoto } \\
\text { Trondh }\end{array}$ & $\begin{array}{l}\text { - Bioti } \\
\text { hjemito }\end{array}$ & \\
\hline $\begin{array}{c}\text { Amostra/ } \\
\text { Mineral }\end{array}$ & AM-03 & $\begin{array}{c}\text { FMR- } \\
01\end{array}$ & $\begin{array}{c}\text { FMR- } \\
03\end{array}$ & $\begin{array}{c}\text { FMR- } \\
05 \mathrm{~A}\end{array}$ & $\begin{array}{c}\text { FMR- } \\
15 \mathrm{~A}\end{array}$ & $\begin{array}{c}\text { FMR- } \\
77\end{array}$ & $\begin{array}{c}\text { FMR- } \\
87\end{array}$ & $\begin{array}{c}\text { FMR- } \\
88\end{array}$ & $\begin{array}{c}\text { FMR- } \\
89\end{array}$ & $\begin{array}{c}\text { FMR- } \\
95\end{array}$ & $\begin{array}{c}\text { FMR- } \\
98\end{array}$ & $\begin{array}{c}\text { FMR- } \\
101\end{array}$ & \begin{tabular}{|c} 
FMR- \\
25
\end{tabular} & $\begin{array}{c}\text { FMR- } \\
27\end{array}$ & $\begin{array}{c}\text { FMR- } \\
52\end{array}$ & $\begin{array}{c}\text { FMR- } \\
37 \mathrm{~A}\end{array}$ & $\begin{array}{c}\text { FMR- } \\
46\end{array}$ & \begin{tabular}{|c} 
FMR- \\
29
\end{tabular} & $\begin{array}{c}\text { FMR- } \\
40\end{array}$ & $\begin{array}{c}\text { FMR- } \\
62 \mathrm{~A}\end{array}$ & $\begin{array}{c}\text { FMR- } \\
32\end{array}$ \\
\hline Plagioclásio & 60,2 & 57,5 & 61,3 & 49,7 & 58,5 & 58,0 & 60,7 & 53,3 & 51,1 & 57,5 & 56,5 & 56,3 & 55,2 & 57,9 & 55,0 & 54,2 & 54,6 & 48,7 & 56,6 & 63,8 & 57,5 \\
\hline Quartzo & 25,1 & 31,8 & 28,5 & 36,4 & 29,5 & 30,5 & 29,1 & 35,2 & 35,0 & 30,2 & 31,1 & 32,4 & 26,3 & 26,5 & 29,5 & 25,0 & 25,6 & 44,8 & 33,3 & 27,0 & 31,0 \\
\hline $\begin{array}{l}\text { Feldspato } \\
\text { Potássico }\end{array}$ & 0,5 & 2,6 & 2,1 & 5,6 & 3,9 & 0,1 & 0,0 & 0,1 & 0,0 & 0,0 & 2,3 & 0,1 & 2,2 & 0,4 & 1,8 & 2,5 & 4,0 & 4,8 & 1,5 & 0,3 & 1,0 \\
\hline Biotita & 11,7 & 4,7 & 4 & 4,5 & 5,2 & 6,7 & 5,4 & 6,6 & 8,0 & 8,5 & 6,3 & 7,7 & 12,9 & 12,1 & 11,7 & 10,7 & 8,8 & 0,7 & 3,4 & 2,9 & 6,7 \\
\hline Epidoto $^{(p)}$ & 0,9 & 1,7 & 0,1 & 1,7 & 0,8 & 0,2 & 0,8 & 1,2 & 0,1 & 0,6 & 0,6 & 0,7 & 1,2 & 1,0 & 0,5 & 1,2 & 1,1 & 0,5 & 0,1 & $\mathrm{X}$ & 0,5 \\
\hline Epidoto $^{(\mathrm{s})}$ & 0,8 & $\mathrm{X}$ & 1,7 & 1,1 & 0,5 & 3,2 & 2,8 & 2,0 & 4,2 & 2,1 & 1,5 & 1,5 & - & 0,1 & 0,5 & 3,1 & 4,9 & $X$ & $\mathrm{X}$ & 2,0 & 2,3 \\
\hline Allanita & $\mathrm{X}$ & 0,1 & 0,1 & $\mathrm{X}$ & $\mathrm{X}$ & - & $X$ & - & - & 0,1 & 0,1 & - & 0,5 & 0,3 & - & $\mathrm{X}$ & - & - & 0,1 & 0,2 & - \\
\hline Apatita & $X$ & 0,2 & 0,3 & 0,4 & 0,3 & 0,1 & $\mathrm{X}$ & 0,1 & 0,2 & 0,1 & 0,3 & 0,2 & 0,1 & 0,6 & 0,2 & 0,6 & 0,1 & 0,2 & $X$ & 0,3 & 0,3 \\
\hline Opacos & $X$ & 0,3 & $X$ & $X$ & 0,2 & 0,3 & $X$ & - & - & $X$ & - & 0,1 & 0,6 & 0,4 & 0,3 & 1,2 & 0,2 & - & - & - & $X$ \\
\hline Titanita & 0,2 & $\mathrm{X}$ & 0,2 & 0,1 & 0,2 & 0,2 & 0,3 & 0,2 & 0,1 & 0,3 & 0,1 & 0,3 & 0,5 & 0,2 & 0,2 & 0,7 & 1,4 & $X$ & 0,1 & 0,5 & $X$ \\
\hline Clorita & 0,3 & 0,1 & 0,2 & 0,2 & - & - & 0,4 & 0,2 & 0,2 & 0,2 & 0,2 & 0,2 & - & - & - & 0,5 & 0,1 & - & 0,2 & 2,3 & 0,4 \\
\hline Zircão & $\mathrm{X}$ & $\mathrm{X}$ & $\mathrm{X}$ & $\mathrm{X}$ & 0,1 & $\mathrm{X}$ & $\mathrm{X}$ & $\mathrm{X}$ & $\mathrm{X}$ & $\mathrm{X}$ & $\mathrm{X}$ & 0,1 & 0,1 & $\mathrm{X}$ & $X$ & $\mathrm{X}$ & $\mathrm{X}$ & $\mathrm{X}$ & $X$ & $\mathrm{X}$ & $\mathrm{X}$ \\
\hline Muscovita & - & - & 0,2 & - & - & - & - & 0,1 & - & - & 0,7 & - & - & - & - & - & - & - & 0,5 & 0,1 & - \\
\hline Carbonato & - & - & 0,1 & - & - & - & - & - & - & - & $\mathrm{X}$ & - & - & - & - & - & - & - & 0,3 & 0,1 & - \\
\hline $\mathrm{A}+\mathrm{P}$ & 60,7 & 60,1 & 63,4 & 55,3 & 62,4 & 58,1 & 60,7 & 53,4 & 51,1 & 57,5 & 58,8 & 56,4 & 57,4 & 58,3 & 56,8 & 56,7 & 58,6 & 53,5 & 58,1 & 64,1 & 58,5 \\
\hline Plagioclásio* & 70,2 & 62,6 & 66,7 & 54,2 & 63,7 & 65,5 & 67,6 & 60,2 & 59,3 & 65,6 & 62,8 & 63,4 & 65,9 & 68,3 & 63,7 & 66,3 & 64,8 & 49,5 & 61,9 & 70,0 & 64,2 \\
\hline Quartzo* & 29,3 & 34,6 & 31,0 & 39,7 & 32,1 & 34,4 & 32,4 & 39,7 & 40,7 & 34,4 & 34,6 & 36,5 & 33,2 & 31,5 & 35,7 & 32,6 & 33,6 & 45,6 & 36,4 & 29,6 & 34,6 \\
\hline $\begin{array}{l}\text { Feldspato } \\
\text { Potássico* }\end{array}$ & 0,6 & 2,8 & 2,3 & 6,1 & 4,2 & 0,1 & 0,0 & 0,1 & 0,0 & 0,0 & 2,6 & 0,1 & 2,6 & 0,5 & 2,1 & 3,1 & 4,8 & 4,9 & 1,6 & 0,3 & 1,1 \\
\hline Máficos & 13,9 & 6,8 & 6,9 & 6,9 & 6,6 & 7,2 & 6,9 & 8,4 & 8,6 & 9,8 & 8,8 & 9,2 & 15,3 & 14,2 & 12,6 & 13,7 & 11,5 & 1,4 & 3,9 & 6,3 & 7,9 \\
\hline
\end{tabular}




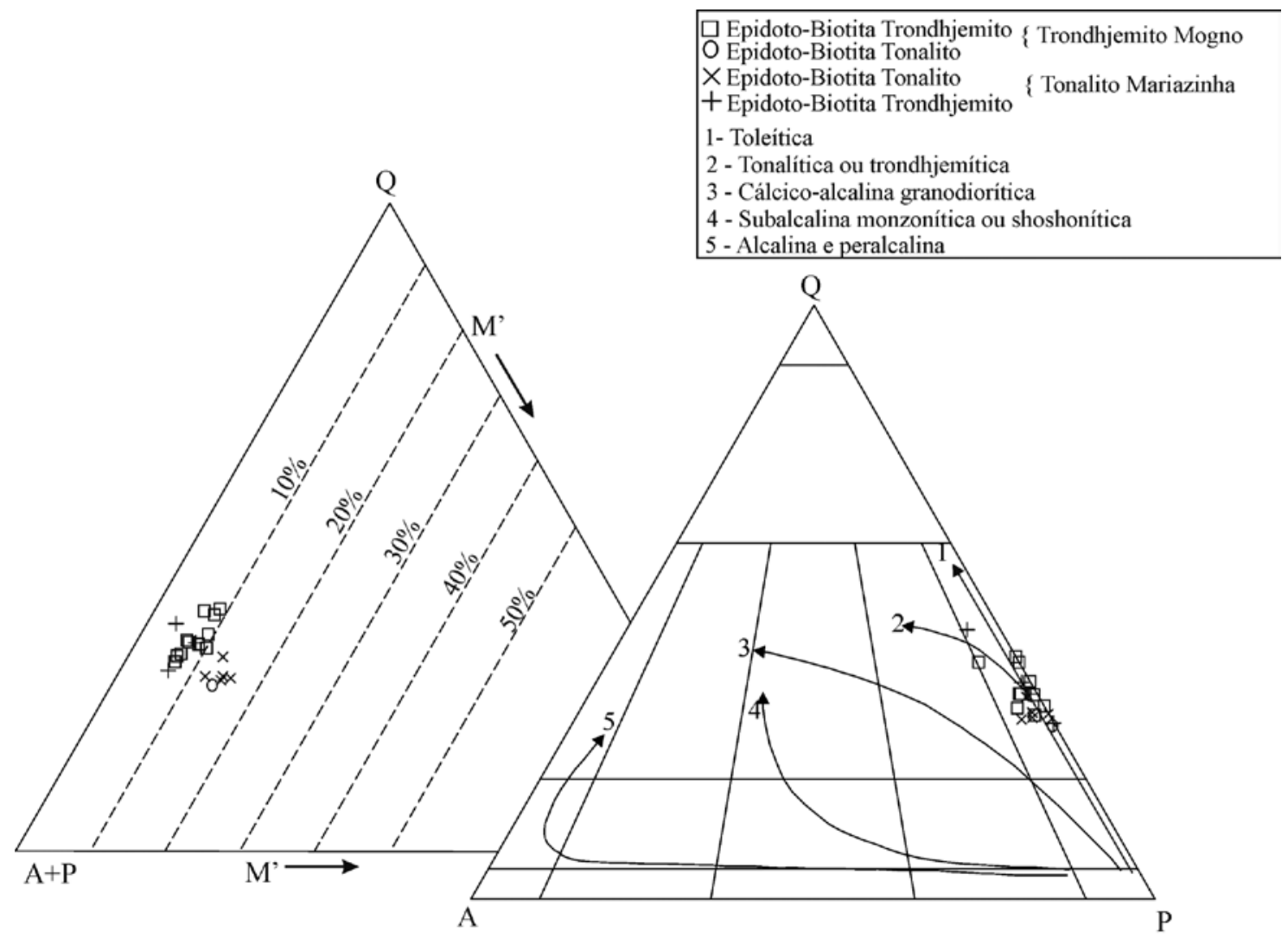

Figura 3 - Diagramas modais Q-A-P e Q-(A+P)-M'(Streckeisen 1976) para as rochas TTG estudadas. 1 a 5 são trends evolutivos de séries granitóides (Lameyre \& Bowden 1982, Bowden et al. 1984).

ausência de anfibólio. Os minerais acessórios compreendem opacos, epidoto, apatita, titanita e allanita e as principais fases secundárias são clorita, epidoto e mica branca. As associações TTG estudadas possuem um comportamento similar ao das séries cálcico- alcalinas trondhjemíticas de baixo potássio (Lameyre \& Bowden 1982) ou cálcico-alcalinas tonalítica-trondhjemíticas (Bowden et al. 1984).

ASPECTOS TEXTURAIS As amostras das associações TTG apresentam notáveis semelhanças texturais, motivo pelo qual serão descritas conjuntamente. A textura característica é granular hipidiomórfica média, modificada em diferentes intensidades pela deformação, ora discreta, afetando apenas o quartzo, ora intensa, gerando texturas protomiloníticas e miloníticas, com forte recristalização do quartzo, formação de subgrãos de plagioclásio e geração de fenoclastos ovalados que são contornados pela matriz fina proveniente de cominuição e recristalização dos grãos primitivos, com a rocha assumindo aspecto fortemente orientado.

Os cristais de quartzo são equigranulares a inequigranulares, hipidiomórficos a xenomórficos, médios a finos $(\leq 3 \mathrm{~mm})$. Exibem contatos irregulares e sinuosos entre si, ondulados com os cristais de plagioclásio e geralmente retilíneos com a biotita. Possuem inclusões de biotita, plagioclásio e zircão. O grau de deformação de seus cristais é variado, apresentando-se, por vezes, subédricos e sem deformação aparente ou levemente estirados acompanhando a direção da foliação, e, em outras, bastante deformados com forte extinção ondulante e formação de subgrãos e novos grãos submilimétricos nas suas bordas.

No Trondhjemito Mogno, o plagioclásio é hipidiomórfico, de dimensões um pouco superiores às do quartzo $(\leq 5 \mathrm{~mm})$ e está bastante saussuritizado, o que mascara as suas feições originais e geminações. Há indícios de zoneamento normal e, subordinadamente, cristais com zoneamento oscilatório. Forma agregados que sugerem relações de synneusis (Vance 1969). Localmente ocorrem mirmequitas nas bordas dos cristais de plagioclásio. No Tonalito Mariazinha, os cristais de plagioclásio são mais límpidos, menos alterados, deformados e recristalizados, do que no Trondhjemito Mogno. Contudo, alguns cristais apresentam discreta extinção ondulante e uma incipiente saussuritização e, local, carbonatação. A alteração é mais intensa no núcleo dos cristais, o que realça seu zoneamento normal. Apresentam contatos irregulares e subordinadamente retilíneos entre si.

O feldspato potássico ocorre como cristais xenomórficos, finos a médios, de contatos ondulantes com os cristais de quartzo e retilíneos entre si. São tardios, intersticiais e pobres em lamelas pertíticas. Apresentam inclusões de plagioclásio e biotita.

A biotita ocorre como lamelas de granulação fina a média, hipidiomórficas, em geral orientadas. Forma agregados com cristais de titanita e epidoto magmático, com os quais apresenta contatos retos. Apresenta-se inclusa em cristais de plagioclásio e feldspato potássico. 
O epidoto ocorre em quatro variedades texturais:

Epidoto I - cristais idiomórficos, prismáticos curtos, às vezes zonados, em geral associados à biotita. Esta costuma exibir contatos retilíneos com o epidoto e pode englobá-lo parcialmente, sugestivo de equilíbrio;

Epidoto II - cristais hipidiomórficos, associados com cristais de allanita e apatita e que, por vezes,englobam núcleos de allanita;

Epidoto III - cristais hipidiomórficos a xenomórficos, em proporções bem reduzidas, isolados ou associados com outros minerais;

Epidoto IV - cristais muito finos, xenomórficos, produto de saussuritização do plagioclásio.

As variedades de Epidoto I, II e III teria origem magmática, enquanto que o Epidoto IV seria formado em condições subsolidus (secundário).

Os minerais acessórios primários compreendem titanita, em cristais hipidiomórficos, finos, associados com agregados de biotita e epidoto ou, por vezes, formando coroas em cristais de opacos, os quais são hipidiomórficos a xenomórficos, e associam-se aos minerais máficos, sendo mais abundantes nos tonalitos; apatita e zircão formam diminutos cristais prismáticos hipidiomórficos a idiomórficos, inclusos em plagioclásio, quartzo e biotita; allanita é euédrica, por vezes, zonada,fraturada e metamictizada.

Os minerais secundários são: mica branca, carbonatos e epidoto, formados a partir do plagioclásio, e clorita, produto de alteração da biotita.

\section{Geoquímica}

ELEMENTOS MAIORES E MENORES Foram realizadas análises químicas de elementos maiores, menores e elementos traço em 19 amostras representativas das associações TTG (Tab. 3). As análises químicas foram realizadas no Laboratório ACME ANALYTICAL LABORATORIES LTD. Os elementos maiores e menores analisados por ICP-ES e os elementos-traço, incluindo os elementos terras raras, foram analisados por ICP-MS (Inductively Coupled Plasma - Mass Spectrometry). Foram utilizados os pacotes analíticos $4 \mathrm{~A}$ e $4 \mathrm{~B}$, sendo os métodos empregados e os limites de detecção informados no site www.acmelab.com.

O Tonalito Mariazinha apresenta maior variação nos conteúdos de sílica $(65,91 \%<\mathrm{SiO} 2<75,25 \%)$, quando comparado ao Trondhjemito Mogno $(68,27 \%<$ $\mathrm{SiO} 2<73,43 \%)$. Os valores médios do somatório dos teores de $\mathrm{Fe}_{2} \mathrm{O}_{3}+\mathrm{MgO}+\mathrm{TiO}_{2}$ são baixos nas duas unidades $(3,24 \%$ no Trondhjemito Mogno e 2,69 e 4,4 $\%$, respectivamente, nos trondhjemitos e tonalitos do Tonalito Mariazinha). Os conteúdos médios de $\mathrm{Al}_{2} \mathrm{O}_{3}$ são superiores a $15 \%$ nos trondhjemitos das duas unidades e atingem $16,32 \%$ no tonalito Mariazinha (Tab. 3), o que caracteriza o conjunto como TTG com alta alumina (Barker 1979). O Trondhjemito Mogno apresenta valores médios da razão $\mathrm{K}_{2} \mathrm{O} / \mathrm{Na}_{2} \mathrm{O}$ de 0,35 (Tab. 3) e o Tonalito Mariazinha fornece valores de 0,30 e 0,26, respectivamente, para tonalitos e trondhjemitos. $\mathrm{O}$ conteúdo médio de $\mathrm{CaO}$ é igual a $2,75 \%$ no Trondhjemito Mogno, e de 2,68 \% nos trondhjemitos, subindo para
$3,55 \%$ nos tonalitos do Tonalito Mariazinha. A proporção média de $\mathrm{Na}_{2} \mathrm{O}$ se situa sempre em torno de $5 \%$ e a de $\mathrm{K}_{2} \mathrm{O}$ é inferior a $2 \%$, decrescendo de 1,92 a $1,68 \%$ do tonalito para os trondhjemitos do Trondhjemito Mogno e de 1,47 a $1,33 \%$ nos tonalitos e trondhjemitos do Tonalito Mariazinha, respectivamente.

Diagramas de Harker (Fig. 4) revelam ligeiro decréscimo dos conteúdos de $\mathrm{Al}_{2} \mathrm{O}_{3}, \mathrm{Na}_{2} \mathrm{O}, \mathrm{CaO}, \mathrm{MgO}$, $\mathrm{Fe}_{2} \mathrm{O}_{3}, \mathrm{TiO}_{2}$ e $\mathrm{P}_{2} \mathrm{O}_{5}$ paralelamente ao aumento de $\mathrm{SiO}_{2}$ nas rochas das duas unidades TTG, mas as mesmas tendem a definir trends distintos, com graus variáveis de superposição, em particular no caso dos trondhjemitos (Figs. 4b, c, d, f). Já o $\mathrm{K}_{2} \mathrm{O}$ mostra correlação negativa com a sílica no Tonalito Mariazinha e positiva no Trondhjemito Mogno (Fig. 4h).

ELEMENTOS TRAÇOS Em séries magmáticas, a variação dos elementos-traço reflete a diferenciação e pode subsidiar a interpretação dos processos responsáveis pela sua evolução (Wedepohl 1970, Hanson 1978), pois a distribuição destes elementos é controlada pelas fases minerais fracionadas durante a gênese e cristalização do magma. O comportamento dos principais elementos-traço dos TTG estudados em diagramas de Harker (Fig. 5) mostra-se muito irregular, com variações muito acentuadas nos conteúdos de diversos elementos em amostras com teores semelhantes de $\mathrm{SiO}_{2}$. De modo geral, $\mathrm{Rb}$ e a razão $\mathrm{Sr} / \mathrm{Ba}$ mostram correlação negativa com a sílica, enquanto que o Ba (Fig. 5d) revela correlação positiva, comportando-se, portanto, como elemento incompatível. O Sr mostra correlação negativa com a sílica (Fig. 5c). $\mathrm{Y}, \mathrm{Yb}$ e $\mathrm{Zr}$ (Figs. 5b, e, f) variam muito pouco nas diferentes variedades, embora algumas amostras, em geral do Trondhjemito Mogno, mostrem teores mais elevados dos dois primeiros. A razão $\mathrm{Rb} / \mathrm{Sr}$ decresce no conjunto de amostras, porém nas duas variedades trondhjemíticas exibe correlação positiva com a sílica (Fig. $5 \mathrm{~h}$ ).

COMPORTAMENTO DOS ELEMENTOS TERRAS RARAS (ETR) Os resultados analíticos de ETR (Tab. 3) foram normalizados pelos valores dos condritos, (Nakamura 1974). Os padrões de ETR (Fig. 6) mostram acentuado enriquecimento em ETR leves em relação aos ETR pesados (Fig. 6), indicativo de fracionamento dos ETR pesadas durante a formação ou diferenciação dos seus magmas. As razões $(\mathrm{La} / \mathrm{Yb}) n$ variam de 14,6 a 93,6 no Trondhjemito Mogno (exceto na amostra FMR$29=10,77)$ e de 29,4 a 93,5 no Tonalito Mariazinha (Tab. 3), (exceto na amostra FMR-101 = 162,38). As anomalias de Eu são ausentes ou muito discretas, podendo ser levemente positivas ou negativas $(0,75<\mathrm{Eu} /$ $\left.\mathrm{Eu}^{*}<1,23\right)$ ou, raramente, acentuadamente positivas (amostras FMR-29 e FMR-52; Eu/Eu* = 3,61 e 1,65, respectivamente). A amostra FMR-29 é a mais rica em sílica de todo o conjunto e exibe acentuado empobrecimento em ETR leves e pesados, juntamente com redução mais moderada de Eu. Isto pode ter sido causado por intenso fracionamento de minerais portadores de ETR e justifica o comportamento anômalo destas amostras, também verificado em termos da razão $(\mathrm{La} / \mathrm{Yb}) n$ 
no caso da amostra FMR-29. O comportamento dominante é perfeitamente compatível com o observado em típicos TTGs arqueanos (Martin 1987, Condie 2005).

CARACTERIZAÇÃO DA SÉRIE MAGMÁTICA No diagrama normativo Ab-An-Or (Fig. 7a), as rochas analisadas se situam nos campos de tonalitos e trondhjemitos e as amostras do Trondhjemito Mogno são mais ricas em Or. Esta distribuição é característica da maioria da cros- ta continental juvenil arqueana, a qual é dominada por associações tonalito-trondhjemito-granodiorito (Jahn et al. 1981, Martin et al. 1983). No diagrama AFM (Fig. 7b), as amostras se situam no campo das séries cálcicoalcalinas (Irvine \& Baragar 1971). No diagrama K-NaCa (Fig. 7c), se posicionam no campo dos trondhjemitos arqueanos (Martin 1994), com as amostras do Tonalito Mariazinha seguindo o trend trondhjemítico e as do Trondhjemito Mogno mostrando paralelismo incipiente

Tabela 3 - Composições químicas dos TTG estudados

\begin{tabular}{|c|c|c|c|c|c|c|c|c|c|c|c|c|c|c|c|c|c|c|c|c|c|c|}
\hline \multirow{2}{*}{$\begin{array}{l}\text { Unidades } \\
\text { Litologia }\end{array}$} & & \multicolumn{11}{|c|}{ Trondhjemito Mogno } & \multicolumn{10}{|c|}{ Tonalito Mariazinha } \\
\hline & $\begin{array}{l}\text { Epidoto } \\
\text { - Biotita } \\
\text { Tonalito }\end{array}$ & \multicolumn{11}{|c|}{ Epidoto -Biotita Trondhjemito } & \multicolumn{6}{|c|}{ Epidoto - Biotita Tonalito } & \multicolumn{4}{|c|}{$\begin{array}{c}\text { Epidoto - Biotita } \\
\text { Thondhjemito }\end{array}$} \\
\hline Amostras & AM-03 & \begin{tabular}{|l} 
FMR- \\
98 \\
\end{tabular} & $\begin{array}{c}\text { FMR } \\
95\end{array}$ & $\begin{array}{c}\text { FMR- } \\
87\end{array}$ & $\begin{array}{c}\text { FMR- } \\
101\end{array}$ & $\begin{array}{c}\text { FMR- } \\
03\end{array}$ & $\begin{array}{c}- \text { FMR- } \\
89 \\
\end{array}$ & $\begin{array}{c}\text { FMR- } \\
05 \mathrm{~A}\end{array}$ & $\begin{array}{c}- \text { FMR- } \\
77 \\
\end{array}$ & $\begin{array}{c}\text { - FMR- } \\
01\end{array}$ & $\begin{array}{r}\text { FMR- } \\
15 \mathrm{~A} \\
\end{array}$ & Média & \begin{tabular}{|c} 
FMR- \\
46
\end{tabular} & $\begin{array}{c}\text { FMR- } \\
27 \\
\end{array}$ & $\begin{array}{c}\text { FMR- } \\
25 \\
\end{array}$ & $\begin{array}{c}\text { FMR- } \\
37 \mathrm{~A}\end{array}$ & $\begin{array}{c}\text { FMR- } \\
52 \\
\end{array}$ & Média & $\begin{array}{c}\text { FMR- } \\
62 \mathrm{~A}\end{array}$ & $\begin{array}{c}\text { - FMR- } \\
32 \\
\end{array}$ & $\begin{array}{c}\text { FMR- } \\
29 \\
\end{array}$ & Média \\
\hline \multicolumn{23}{|l|}{ Elementos } \\
\hline \multicolumn{23}{|l|}{ (\% peso) } \\
\hline $\mathrm{SiO}_{2}$ & 68,27 & 68,99 & 69 & 70,01 & 70,2 & 71,32 & 271,35 & 71 & 271 & 972 , & 873,43 & 371,06 & 65,91 & 68,06 & 68,58 & 69,22 & 70,11 & 168,38 & 69,67 & 770,83 & 75,25 & 571,92 \\
\hline $\mathrm{TiO}_{2}$ & 0,35 & 0,42 & 0,35 & 0,29 & 0,29 & 0,21 & 0,23 & 0,25 & 0,24 & 0,22 & 0,23 & 0,27 & 0,63 & 0,35 & 0,31 & 0,32 & 0,26 & 0,37 & 0,32 & 0,31 & 0,03 & 0,22 \\
\hline $\mathrm{Al}_{2} \mathrm{O}_{3}$ & 15,14 & 14,82 & 15,63 & 16,19 & 16,10 & 14,82 & 215,48 & 15,21 & 115,33 & 314,94 & 414,25 & 515,28 & 15,93 & 316,74 & $+16,63$ & 16,26 & 16,04 & 416,32 & 15,75 & 515,16 & 14,77 & 715,23 \\
\hline $\mathrm{Fe}_{2} \mathrm{O}_{3}$ & 3,13 & 3,61 & 2,76 & 2,08 & 2,33 & 2,10 & 1,84 & 2,02 & 1,94 & 2,06 & 2,01 & 2,28 & 4,10 & 2,94 & 2,75 & 2,85 & 2,58 & 3,04 & 2,55 & 2,80 & 0,48 & 1,94 \\
\hline $\mathrm{MnO}$ & 0,05 & 0,05 & 0,03 & 0,03 & 0,03 & 0,03 & 0,02 & 0,03 & 0,03 & 0,03 & 0,02 & 0,03 & 0,04 & 0,05 & 0,04 & 0,03 & 0,04 & 0,04 & 0,03 & 0,03 & $<0,01$ & 10,03 \\
\hline $\mathrm{MgO}$ & 1,23 & 1,15 & 0,95 & 0,66 & 0,76 & 0,57 & 0,57 & 0,55 & 0,58 & 0,55 & 0,52 & 0,69 & 1,39 & 1,01 & 0,91 & 0,87 & 0,77 & 0,99 & 0,83 & 0,71 & 0,05 & 0,53 \\
\hline $\mathrm{CaO}$ & 2,92 & 2,23 & 3,18 & 3,09 & 3,26 & 2,18 & 2,96 & 2,97 & 2,79 & 2,49 & 2,37 & 2,75 & 3,90 & 3,22 & 3,49 & 3,78 & 3,36 & 3,55 & 3,08 & 3,07 & 1,89 & 2,68 \\
\hline $\mathrm{Na}_{2} \mathrm{O}$ & 4,52 & 5,40 & 4,46 & 5,44 & 5,09 & 4,70 & 5,03 & 4,63 & 4,88 & 4,52 & 4,52 & 4,87 & 4,51 & 5,64 & 5,18 & 4,88 & 5,07 & 5,06 & 4,88 & 4,84 & 5,64 & 5,12 \\
\hline $\mathrm{K}_{2} \mathrm{O}$ & 1,92 & 1,58 & 1,74 & 1,24 & 1,23 & 2,12 & 1,31 & 1,89 & 1,58 & 2,16 & 1,90 & 1,68 & 2,27 & 1,24 & 1,52 & 1,11 & 1,20 & 1,47 & 1,36 & 1,39 & 1,23 & 1,33 \\
\hline $\mathrm{P}_{2} \mathrm{O}_{5}$ & 0,10 & 0,16 & 0,09 & 0,10 & 0,09 & 0,08 & 0,08 & 0,07 & 0,09 & 0,06 & 0,07 & 0,09 & 0,19 & 0,11 & 0,12 & 0,10 & 0,08 & 0,12 & 0,10 & 0,10 & 0,02 & 0,07 \\
\hline PF & 2,10 & 1,30 & 0,90 & 0,70 & 0,40 & 1,60 & 1,00 & 0,60 & 0,70 & 0,70 & 0,60 & 0,85 & 0,90 & 0,50 & 0,30 & 0,40 & 0,30 & 0,48 & 1,30 & 0,60 & 0,50 & 0,80 \\
\hline Total & 99,73 & 99,71 & 99,88 & 99,83 & 399,86 & 99,73 & 399,87 & 99,84 & 499,85 & 599,81 & 199,92 & 299,83 & 99,77 & 799,86 & 599,83 & 399,82 & 99,81 & 199,82 & 99,87 & 799,84 & 99,86 & 599,86 \\
\hline \multicolumn{23}{|l|}{$(\mathrm{ppm})$} \\
\hline $\mathrm{Ba}$ & 641 & 531 & 584 & 534 & 487 & 794 & 568 & 678 & 472 & 666 & 793 & 611 & 918 & 173 & 388 & 418 & 626 & 505 & 464 & 429 & 727 & 540 \\
\hline $\mathrm{Sr}$ & 434 & 355 & 387 & 668 & 554 & 431 & 520 & 515 & 506 & 499 & 533 & 497 & 592 & 521 & 771 & 517 & 434 & 567 & 626 & 504 & 650 & 593 \\
\hline $\mathrm{Rb}$ & 52,5 & 57,8 & 37,0 & 25,4 & 27,9 & 48,9 & 41,3 & 41,4 & 24,2 & 47,1 & 39,9 & 39,1 & 67,3 & 56,3 & 51,2 & 38,3 & 36,8 & 50,0 & 38,8 & 42,6 & 18,2 & 33,2 \\
\hline $\mathrm{Zr}$ & 174 & 150 & 135 & 140 & 141 & 114 & 104 & 114 & 129 & 109 & 126 & 126 & 136 & 137 & 146 & 149 & 109 & 135 & 145 & 196 & 40 & 127 \\
\hline $\mathrm{Y}$ & 9,7 & 5,1 & 4,3 & 2,9 & 2,7 & 9,7 & 8,6 & 11,3 & 4,3 & 6,4 & 2,6 & 5,8 & 8,6 & 4,3 & 3,3 & 3,8 & 1,7 & 4,3 & 7,2 & 3,5 & 0,8 & 3,8 \\
\hline $\mathrm{Nb}$ & 3,8 & 5,5 & 3,9 & 2,7 & 2,3 & 4,0 & 2,5 & 4,3 & 1,6 & 3,7 & 2,4 & 3,3 & 6,5 & 3,0 & 3,2 & 1,9 & 2,8 & 3,5 & 3,8 & 2,4 & 0,5 & 2,2 \\
\hline $\mathrm{La}$ & 21,60 & & & & & & & & 023,40 & 024,60 & 033,70 & 29,49 & 32,60 & 46,10 & 33,40 & 15,10 & 9,70 & 27,38 & 26,70 & 044,90 & 2,10 & 24,57 \\
\hline $\mathrm{Ce}$ & 35,20 & 70,80 & & & & & & & & & & & 60,00 & & & 27,90 & 18,50 & 050,64 & 46,00 & 78,10 & 3,10 & 42,40 \\
\hline $\operatorname{Pr}$ & 5,04 & 7,72 & 5,50 & 4,61 & 5,90 & 5,09 & 8,81 & 3,56 & 4,83 & 5,25 & 6,59 & 5,79 & 7,45 & 9,22 & 6,57 & 3,04 & 1,92 & 5,64 & 5,60 & 7,83 & 0,40 & 4,61 \\
\hline $\mathrm{Nd}$ & 18,40 & 26,80 & 19,20 & 16,20 & 19,10 & & 032,60 & 15,00 & 017,00 & 17,90 & 22,60 & 20,43 & 30,50 & 32,30 & 24,10 & 11,50 & 5,90 & 20,86 & 22,00 & 28,60 & 1,60 & 17,40 \\
\hline $\mathrm{Sm}$ & 2,98 & 3,51 & 2,36 & 1,89 & 2,25 & 2,81 & 4,37 & 2,66 & 2,21 & 2,58 & 2,45 & 2,71 & 4,43 & 3,70 & 2,83 & 1,54 & 1,05 & 2,71 & 2,98 & 3,40 & 0,10 & 2,16 \\
\hline $\mathrm{Eu}$ & 0,93 & 0,68 & 0,55 & 0,58 & 0,71 & 0,70 & 1,55 & 0,74 & 0,51 & 0,61 & 0,54 & 0,72 & 1,11 & 0,77 & 0,64 & 0,57 & 0,51 & 0,72 & 0,73 & 0,81 & 0,17 & 0,57 \\
\hline $\mathrm{Gd}$ & 2,28 & 2,23 & 1,72 & 1,32 & 1,57 & 2,26 & 3,41 & 2,80 & 1,42 & 2,10 & 1,70 & 2,05 & 3,63 & 2,43 & 1,87 & 1,42 & 0,86 & 2,04 & 2,59 & 2,28 & 0,21 & 1,69 \\
\hline $\mathrm{Tb}$ & 0,34 & 0,26 & 0,20 & 0,13 & 0,14 & 0,32 & 0,44 & 0,40 & 0,16 & 0,26 & 0,13 & 0,24 & 0,40 & 0,22 & 0,15 & 0,15 & 0,10 & 0,20 & 0,34 & 0,20 & 0,02 & 0,19 \\
\hline Dy & 1,68 & 1,07 & 1,01 & 0,58 & 0,69 & 1,47 & 2,27 & 2,26 & 0,59 & 1,45 & 0,54 & 1,19 & 1,41 & 1,14 & 0,72 & 0,69 & 0,48 & 0,89 & 1,44 & 0,85 & 0,16 & 0,82 \\
\hline Ho & 0,33 & 0,16 & 0,13 & 0,10 & 0,10 & 0,27 & 0,36 & 0,38 & 0,13 & 0,23 & 0,10 & 0,20 & 0,25 & 0,15 & 0,11 & 0,11 & 0,07 & 0,14 & 0,25 & 0,12 & 0,02 & 0,13 \\
\hline $\mathrm{Er}$ & 0,85 & 0,42 & 0,39 & 0,24 & 0,27 & 0,76 & 0,89 & 0,98 & 0,38 & 0,59 & 0,17 & 0,51 & 0,54 & 0,42 & 0,33 & 0,26 & 0,16 & 0,34 & 0,60 & 0,45 & 0,11 & 0,39 \\
\hline $\mathrm{Tm}$ & 0,13 & 0,06 & 0,06 & 0,04 & 0,03 & 0,11 & 0,15 & 0,13 & 0,06 & 0,08 & 0,04 & 0,08 & 0,07 & 0,04 & 0,06 & 0,05 & 0,03 & 0,05 & 0,08 & 0,05 & 0,01 & 0,05 \\
\hline $\mathrm{Yb}$ & 0,76 & 0,36 & 0,30 & 0,27 & 0,14 & 0,65 & 0,86 & 0,73 & 0,30 & 0,59 & 0,24 & 0,44 & 0,40 & 0,34 & 0,24 & 0,24 & 0,22 & 0,29 & 0,42 & 0,32 & 0,13 & 0,29 \\
\hline $\mathrm{Lu}$ & 0,11 & 0,05 & 0,06 & 0,03 & 0,04 & 0,10 & 0,13 & 0,12 & 0,05 & 0,08 & 0,03 & 0,07 & 0,04 & 0,04 & 0,04 & 0,03 & 0,02 & 0,03 & 0,06 & 0,05 & 0,02 & 0,04 \\
\hline$\sum$ ETRL & 83,2 & 147,9 & 102,2 & 86,9 & 102,0 & 86,1 & 124,3 & 65,6 & 91,3 & 89,3 & 126,8 & 8102,2 & 135,0 & 177,1 & 127,9 & 59,1 & 37,1 & 107,2 & 103,3 & 3162,8 & 7,3 & 91,1 \\
\hline$(\mathrm{La} / \mathrm{Yb}) \mathrm{n}$ & 72,4 & 26,1 & 60,0 & 58,3 & 162,4 & 19,0 & 37,2 & 14,6 & 52,0 & 27,8 & 93,6 & 55,1 & 54,3 & 90,4 & 92,8 & 41,9 & 29,4 & 61,8 & 42,4 & 93,5 & 10,8 & 48,9 \\
\hline$(\mathrm{La} / \mathrm{Sm}) \mathrm{n}$ & 4,5 & 6,9 & 7,0 & 7,7 & 9,3 & 5,6 & 6,8 & 3,7 & 6,5 & 5,9 & 8,5 & 6,8 & 4,5 & 7,7 & 7,3 & 6,0 & 5,7 & 6,2 & 5,5 & 8,1 & 12,9 & 8,9 \\
\hline$(\mathrm{Dy} / \mathrm{Yb}) \mathrm{n}$ & 1,4 & 1,9 & 2,2 & 1,4 & 3,1 & 0,3 & 1,7 & 2,0 & 1,3 & 1,6 & 1,4 & 1,7 & 2,3 & 2,1 & 1,9 & 1,8 & 1,4 & 1,9 & 2,2 & 1,7 & 0,8 & 1,6 \\
\hline $\mathrm{Eu} / \mathrm{Eu}^{*}$ & 1,10 & 0,75 & 0,84 & 1,13 & 1,16 & 0,85 & 1,23 & 0,83 & 0,88 & 0,81 & 0,81 & 0,93 & 0,85 & 0,79 & 0,86 & 1,18 & 1,65 & 1,07 & 0,81 & 0,89 & 3,61 & 1,77 \\
\hline $\mathrm{Rb} / \mathrm{Sr}$ & 0,12 & 0,16 & 0,10 & 0,04 & 0,05 & 0,11 & 0,08 & 0,08 & 0,05 & 0,09 & 0,07 & 0,08 & 0,11 & 0,11 & 0,07 & 0,07 & 0,08 & 0,09 & 0,06 & 0,08 & 0,03 & 0,06 \\
\hline $\mathrm{Sr} / \mathrm{Ba}$ & 0,68 & 0,67 & 0,66 & 1,25 & 1,14 & 0,54 & 0,92 & 0,76 & 1,07 & 0,75 & 0,67 & 0,84 & 0,64 & 3,01 & 1,99 & 1,24 & 0,69 & 1,51 & 1,35 & 1,18 & 0,89 & 1,14 \\
\hline $\mathrm{K}_{2} \mathrm{O} / \mathrm{Na}_{2} \mathrm{O}$ & 0,42 & 0,29 & 0,39 & 0,23 & 0,24 & 0,45 & 0,26 & 0,41 & 0,32 & 0,48 & 0,42 & 0,35 & 0,50 & 0,22 & 0,29 & 0,23 & 0,24 & 0,30 & 0,28 & 0,29 & 0,22 & 0,26 \\
\hline$\# \mathrm{Mg}$ & 0,43 & 0,38 & 0,40 & 0,38 & 0,39 & 0,34 & 0,38 & 0,35 & 0,37 & 0,34 & 0,34 & 0,37 & 0,40 & 0,40 & 0,39 & 0,37 & 0,37 & 0,39 & 0,39 & 0,33 & 0,17 & 0,30 \\
\hline
\end{tabular}



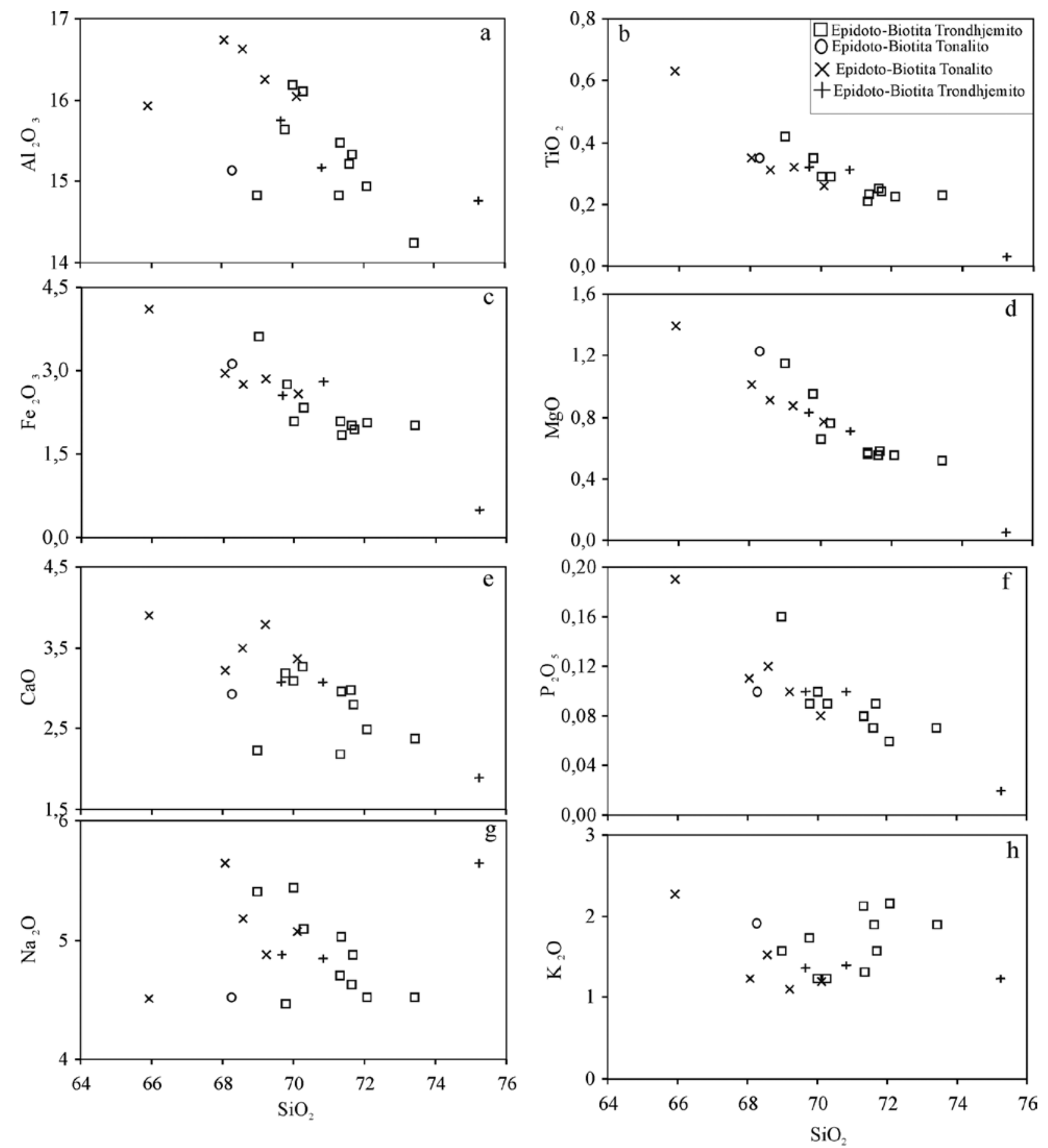

Figura 4 - Diagramas tipo Harker para elementos maiores e menores dos TTG estudados.

com o trend cálcico-alcalino (Nockolds \& Allen 1953, Barker \& Arth 1976). Apresentam número de \#Mg variando de 0,40 a 0,33 , com uma única amostra destoante (FMR-29 = 0,17). Os valores de \#Mg tendem a ser ligeiramente mais elevados nas amostras do Tonalito Mariazinha do que no Trondhjemito Mogno.

No diagrama $\mathrm{Al}_{2} \mathrm{O}_{3} /\left(\mathrm{CaO}+\mathrm{Na}_{2} \mathrm{O}+\mathrm{K}_{2} \mathrm{O}\right)$ vs. $\mathrm{Al}_{2} \mathrm{O}_{3} /\left(\mathrm{Na}_{2} \mathrm{O}+\mathrm{K}_{2} \mathrm{O}\right)$ (Fig. 8a), baseado no índice de Shand, com os óxidos expressos em proporções moleculares, observa-se que as amostras de ambas as associações posicionam-se no campo peraluminoso, mas próximas ao limite do campo metaluminoso. No dia- grama $\mathrm{K}_{2} \mathrm{O}$ vs. $\mathrm{SiO}_{2}$, situam-se nos campos das rochas de baixo a médio $\mathrm{K}$ (Fig. $8 \mathrm{~b}$ ), com destaque para o enriquecimento relativo em $\mathrm{K}_{2} \mathrm{O}$ em algumas amostras do Trondhjemito Mogno. O diagrama $\mathrm{A} / \mathrm{CNK}$ vs. $\mathrm{K} /$ $\mathrm{Na}$ (Fig. 8c) também individualiza bem as duas associações TTG, em função, principalmente, das maiores razões K/Na no Trondhjemito Mogno. Já o diagrama \#Mg vs. $\mathrm{K} / \mathrm{Na}$ mostra que ambas unidades apresentam valores similares de \#Mg.

\section{DISCUSSÕES}

Revisão do significado do Trondhjemito Mogno e 

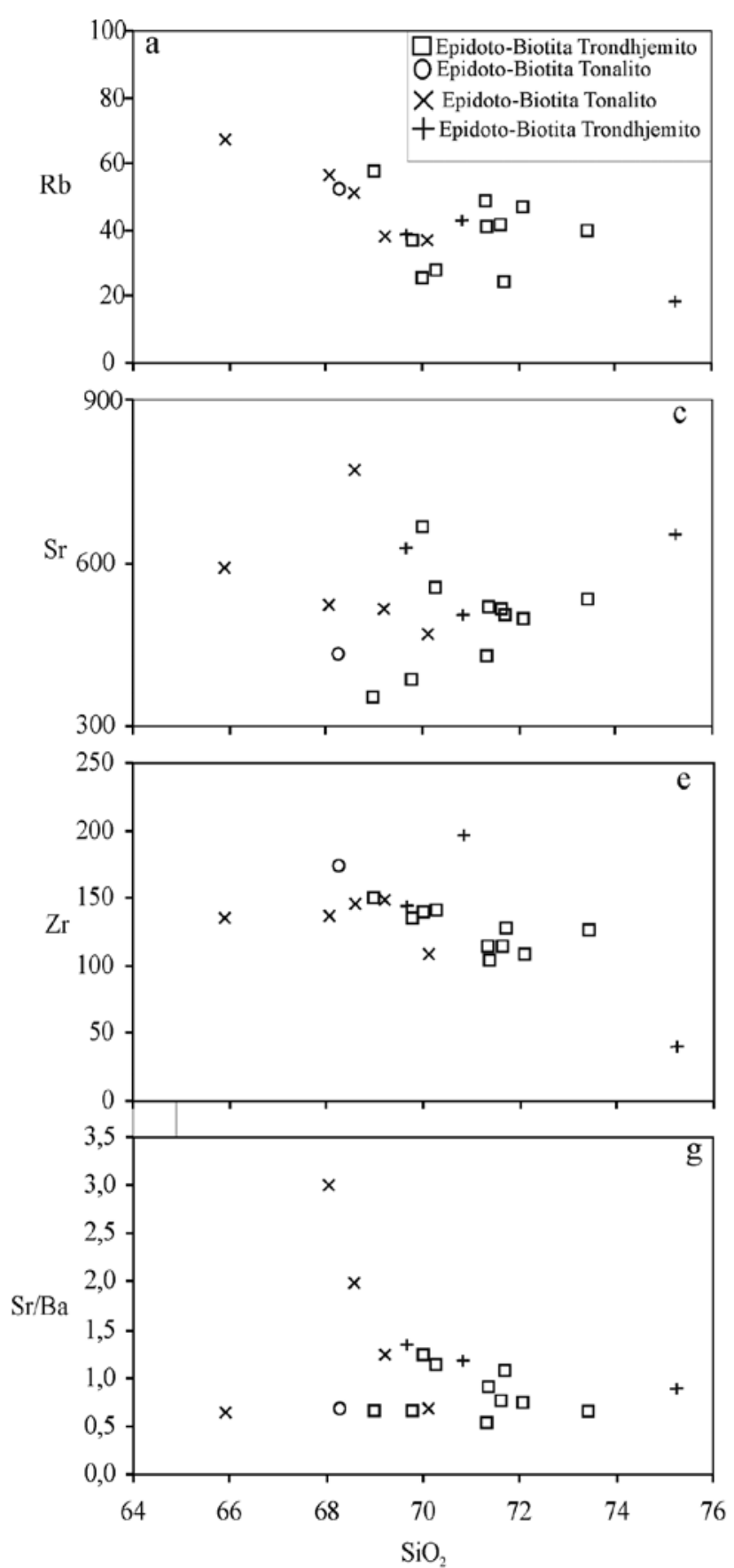
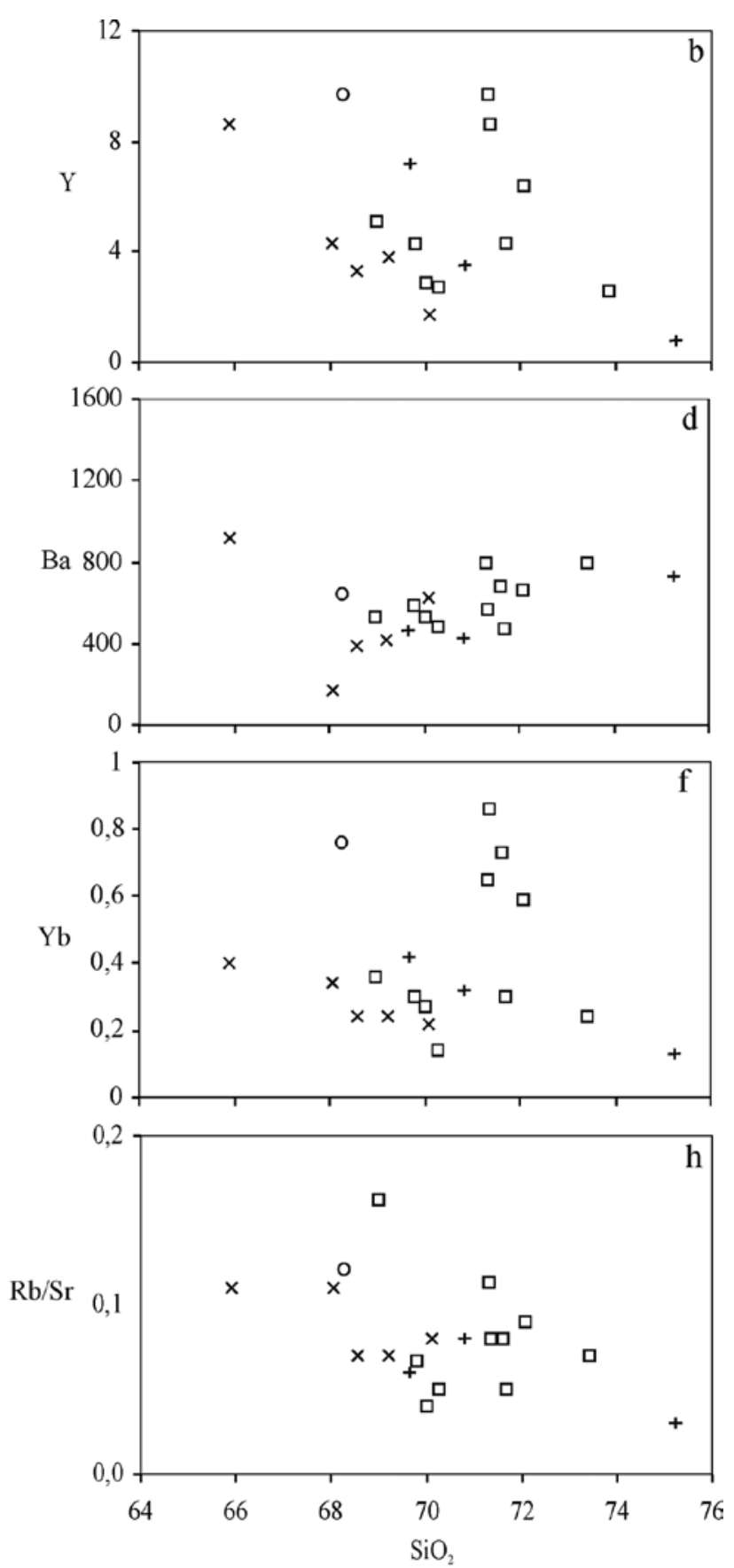

Figura 5 - Diagramas tipo Harker para elementos traços dos TTG estudados.

definição de nova unidade TTG Os mapas geológicos anteriores ao presente trabalho indicavam que o Trondhjemito Mogno apresentava notável homogeneidade, cobria grande extensão no TGGRM e era associado temporalmente à segunda geração de TTGs do TGGRM, com idade próxima de $2,87 \mathrm{Ga}$ (Huhn et al. 1988, Souza 1994, Leite et al. 2004, Dall'Agnol et al. 2006, Vasquez et al. 2008). Entretanto, mapeamento geológico de maior detalhe, acompanhado de estudos de petrografia, geoquímica e geocronologia, permitiu a identificação de duas associações TTG distintas no domínio do Trondhjemito Mogno. Isto teve diversas conseqüências: Foi reduzida a área de ocorrência do Trondhjemito Mogno (Fig. 2); criou-se a necessidade de proposição de nova associação TTG (Tonalito Mariazinha); implicou rever a idade e o posicionamento estratigráfico do Trondhjemito Mogno.

Propõe-se, neste trabalho, que a distribuição do Trondhjemito Mogno seja mantida no seu antigo domínio leste, seja interrompida no domínio central, onde dá lugar ao Tonalito Mariazinha, e tenha continuidade na porção oeste de sua antiga área de ocorrência (Fig. 2). Além disso, os novos dados geocronológicos obtidos por Almeida (2010) revelam que a idade de cristalização do Trondhjemito Mogno é próxima de 2,96 Ga (Tab. 1) e, portanto, não se correlaciona com a segunda geração dos TTGs do TGGRM. Estes passaram a ter distribuição areal muito restrita e se limitam aoTron- 

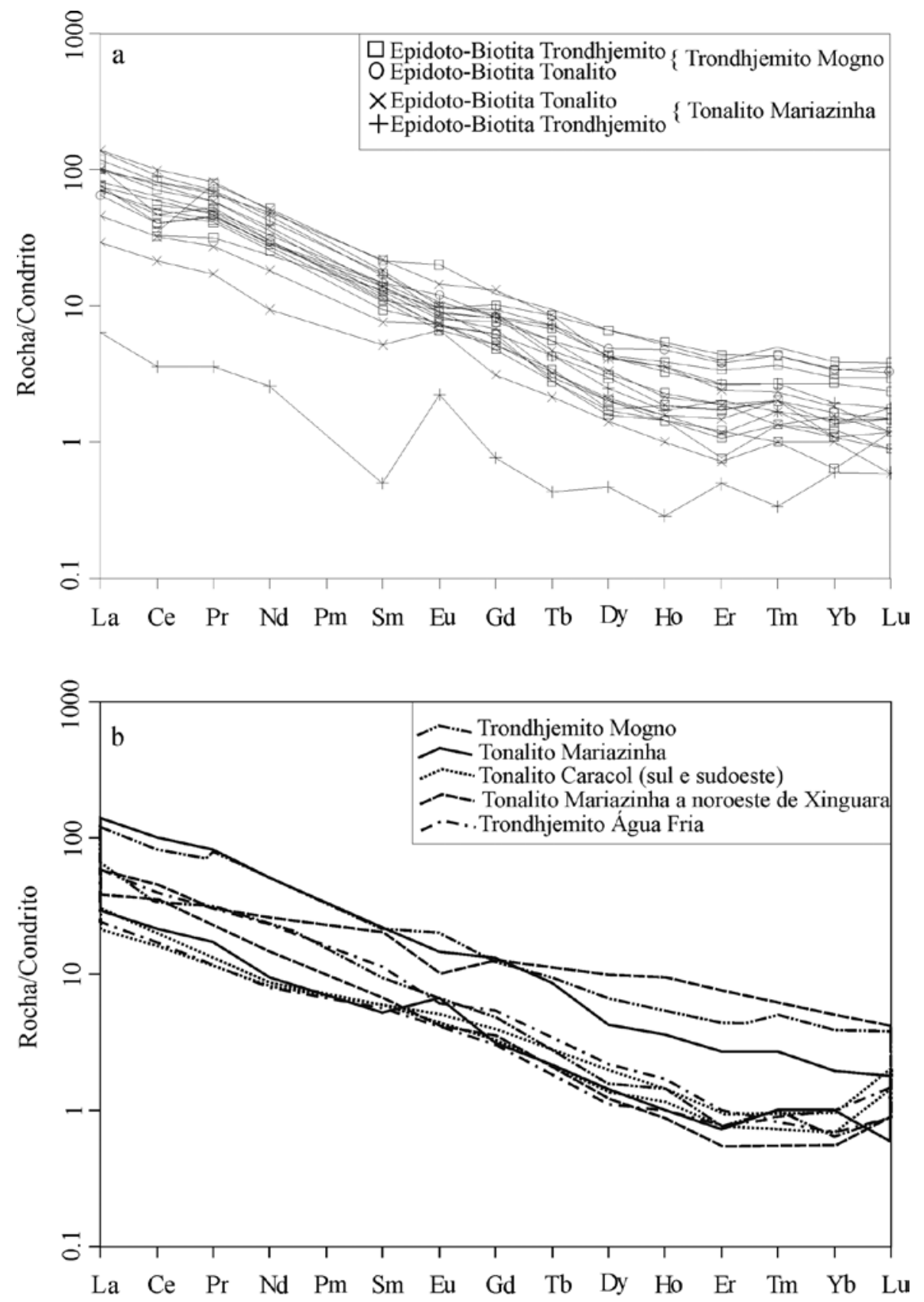

Figura 6 - a) Padrões de elementos terras raras dos TTG estudados; b) Comparação entre os padrões de elementos terras raras das rochas TTG estudadas com aqueles dos TTG da região de Xinguara (Leite 2001). Dados normalizados em relação ao condrito (Nakamura 1974).

dhjemito Água Fria. Preferiu-se manter a designação de Trondhjemito Mogno e assim evitar a indesejável proliferação de nomes estratigráficos.

O Tonalito Mariazinha se distingue do Trondhjemito Mogno por apresentar padrão estrutural divergente, com marcante orientação NE-SW ou NS, discordante do padrão dominante no TGGRM (Fig. 2). Além disso, sua idade de $2925 \pm 4$ Ma (Tab. 1; Almeida, 2010), destoa da obtida para o Trondhjemito Mogno. Tanto a idade quanto o padrão estrutural apresentado pelo Tonalito Mariazinha diferem daqueles apresentados pelo Complexo Tonalítico Caracol em suas ocor- rências do sul de Xinguara. Isto impede a correlação entre as duas unidades. Porém, um pequeno corpo TTG situado a NW do corpo Xinguara (Leite 2001, Leite et al. 2004), apresenta idade e padrão estrutural coincidentes com os do Tonalito Mariazinha e foi, por esta razão, a ele correlacionado (Almeida 2010).

Assim, propomos a criação de uma nova unidade estratigráfica, denominada Tonalito Mariazinha, cuja área-tipo se situa ao longo da estrada de direção NE que liga as nascentes do Rio Maria e do Ribeirão Caracol (Fig. 2). 

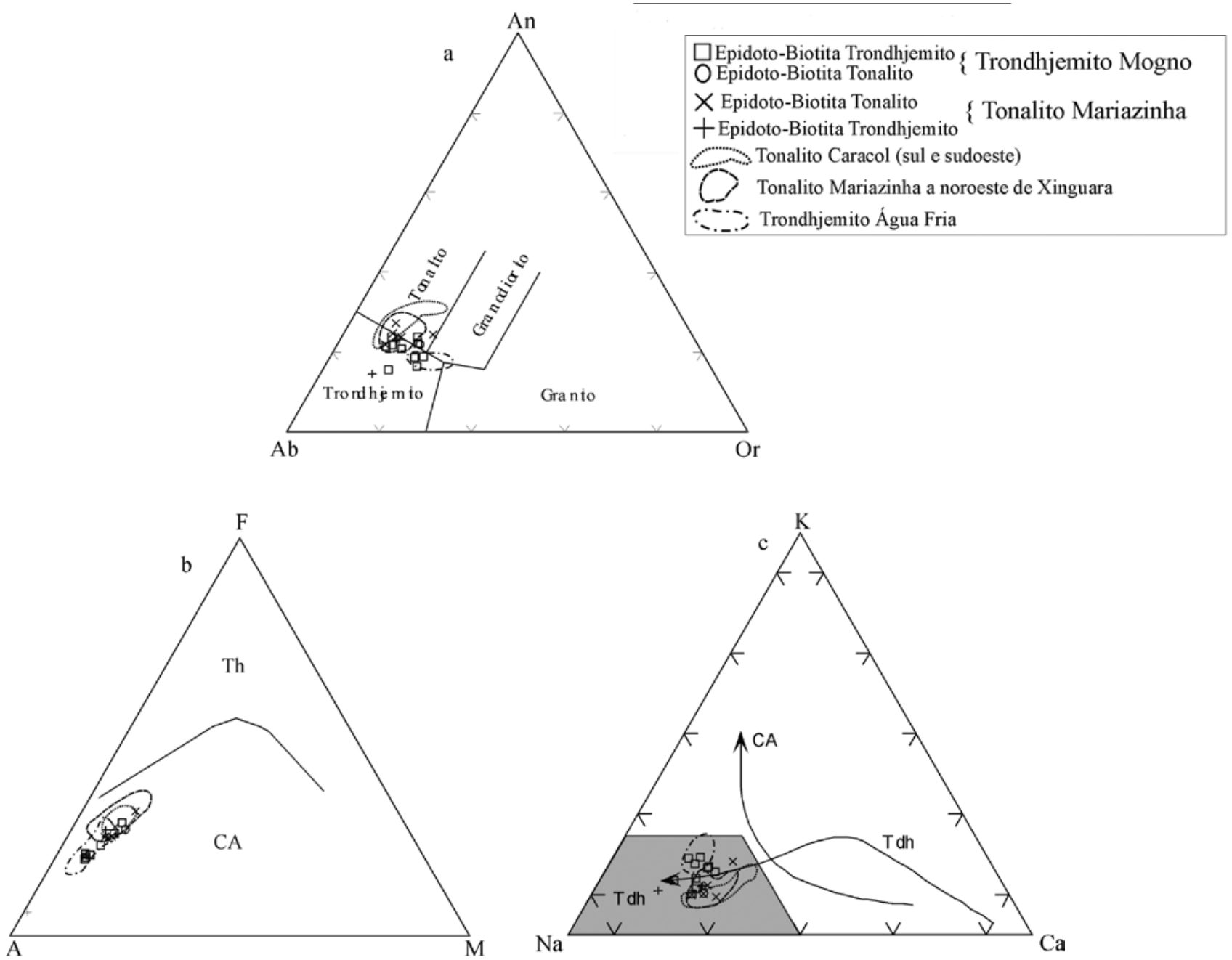

Figura 7 - Caracterização geoquímica das rochas TTG estudadas: a) Diagrama Ab-An-Or normativo (O'Connor 1965, com campos de Barker 1979). b) Diagrama $\mathrm{AFM}\left(\mathrm{A}=\mathrm{Na}_{2} \mathrm{O}+\mathrm{K}_{2} \mathrm{O} ; \mathrm{F}=\mathrm{FeO}+0,9 * \mathrm{Fe}_{2} \mathrm{O} 3 ; \mathrm{M}=\mathrm{MgO}\right) \mathrm{com}$ campos de Irvine \& Baragar (1971): Th= Toleitos, $C A=$ cálcico-alcalino; c) Diagrama K-Na-Ca; campo Tdh dos TTGs típicos (Martin 1994), Tdh = trend trondhjemitico de Barker \& Arth (1976) e CA= trend cálcico-alcalino.

Comparações com outras associações TTG do TGGRM O Complexo Tonalítico Caracol e o Trondhjemito Água Fria (Leite 2001) que afloram na região de Xinguara foram escolhidos para comparações petrográficas e geoquímicas com as associações TTG estudadas neste trabalho por, serem duas associações TTG melhor estudadas e representativas, respectivamente, da primeira e segunda geração de TTG do TGGRM.

As associações TTG estudadas neste trabalho não diferem acentuadamente em termos de composição modal das demais ocorrências mencionadas, pois todas são tonalitos e trondhjemitos, com raros termos granodioríticos, e contêm como principal mineral ferromagnesiano a biotita, geralmente acompanhada por epidoto magmático. Entretanto, os diagramas geoquímicos (Figs. 7 e 8) revelam algumas diferenças e afinidades que merecem destaque. O Tonalito Caracol e Tonalito Mariazinha possuem grande afinidade geoquímica, pois há uma nítida tendência à superposição entre os campos definidos pelas amostras de ambos. Constata-se também uma marcante superposição entre as amostras do Tonalito Mariazinha do corpo do noroeste do pluton Xinguara e aquelas da área-tipo. Quanto ao Trondhjemito Mogno, suas amostras menos evoluídas se superpõem parcialmente com o campo do Tonalito Caracol, enquanto que as mais ricas em $\mathrm{K}_{2} \mathrm{O}$ se distribuem nos vários diagramas considerados em campo coincidente com o do Trondhjemito Água Fria. Por outro lado, tanto o Trondhjemito Mogno, quanto o Tonalito Mariazinha possuem Mg\# relativamente elevado e próximo daquele das amostras do Complexo Tonalítico Caracol (Fig. 8d).

Os padrões de elementos terras raras mostram grande semelhança nas várias associações TTG (Fig. 6b), sendo marcante o enriquecimento acentuado em ETR leves em relação aos ETR pesados, com fracionamento moderado a acentuado dos ETR pesados e fraca a ausente anomalia de Eu.

CONCLUSÕES Os dados de campo, petrográficos, geoquímicos e geocronológicos apresentados ou discutidos neste trabalho permitem alcançar as seguintes conclusões:

(1) O Trondhjemito Mogno, tido como um 

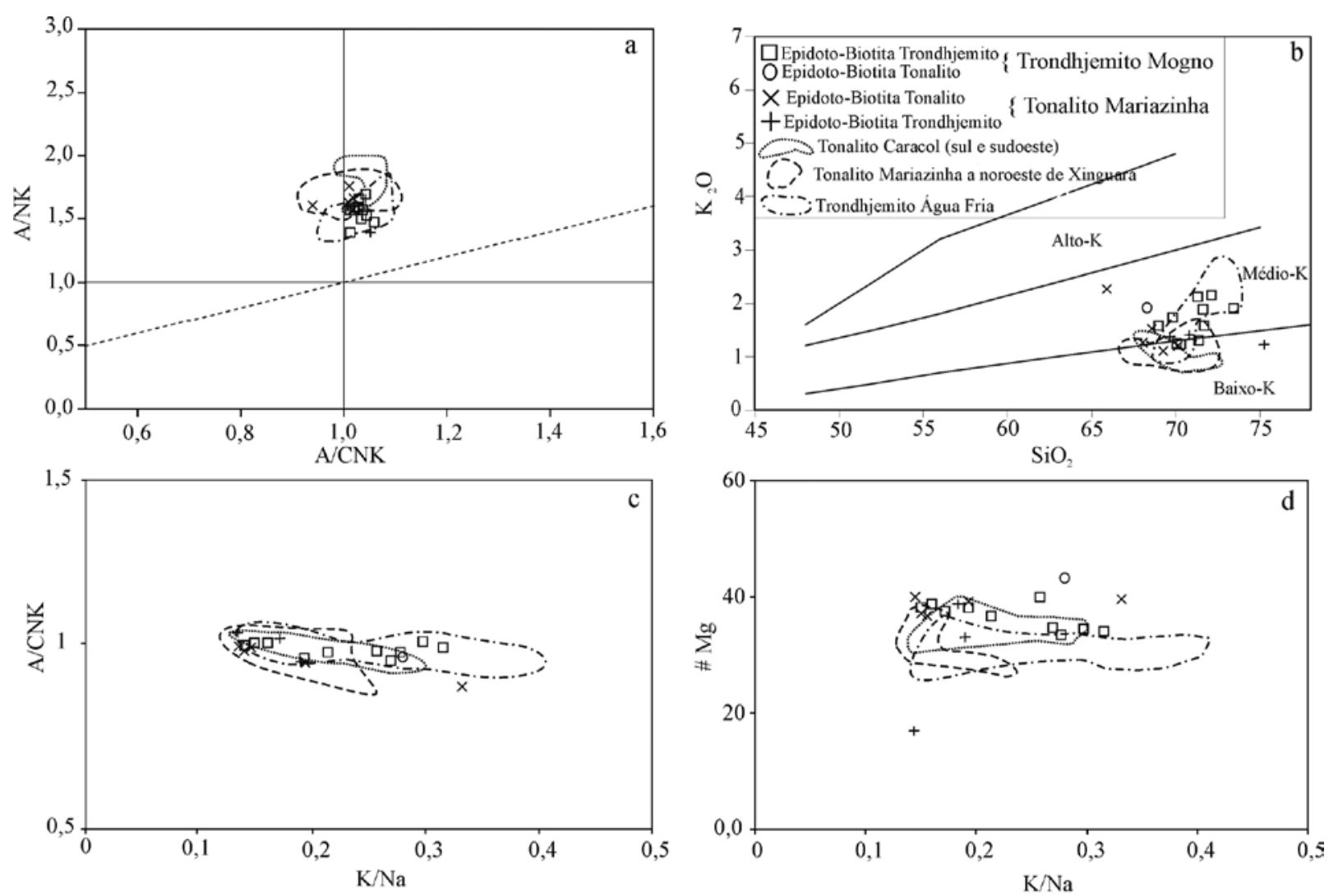

Figura 8 - Diagramas de caracterização geoquímica dos TTG estudados: a) Diagrama [Al_O_ $\left.\left(\mathrm{CaO}+\mathrm{Na}_{2} \mathrm{O}+\mathrm{K}_{2} \mathrm{O}\right)\right] \mathrm{mol}$ vs. $\left[\mathrm{Al}_{2} \mathrm{O}_{3}\left(\mathrm{Na}_{2} \mathrm{O}+\mathrm{K}_{2} \mathrm{O}\right)\right] \mathrm{mol}$; b) Diagrama binário $\mathrm{K}_{2} \mathrm{O}$ vs. $\mathrm{SiO}_{2}$ (Peccerillo \& Taylor 1976); c) Diagrama A/CNK vs. K/Na, d) Diagrama \#Mg vs. K/Na. K/Ne, \#Mg razões moleculares.

corpo muito homogêneo apresenta em sua principal área de ocorrência diferenças que levaram à sua separação em duas associações TTG distintas. A designação de Trondhjemito Mogno foi mantida para a associação dominante, com padrão estrutural NW-SE a EW, distribuída nos domínios leste e oeste da área mapeada. A nova associação identificada na porção centro-oeste da área mapeada, com foliação dominante NE-SW e NS, foi denominada de Tonalito Mariazinha, uma nova unidade estratigráfica, e ficou bastante reduzida a área de ocorrência do Trondhjemito Mogno na região;

(2) Os dados geocronológicos obtidos por Almeida (2010) revelaram que o Trondhjemito Mogno e o Tonalito Mariazinha não fazem parte da segunda geração de TTGs do TGGRM;

(3) As duas associações TTG estudadas se situam sempre no campo dos tonalitos-trondhjemitos no diagrama QAP e possuem biotita como principal mineral ferromagnesiano.

(4) Geoquimicamente, os tonalitos e trondhjemitos pertencem ao grupo de TTG com alto $\mathrm{Al}_{2} \mathrm{O}_{3}$, são relativamente pobres em elementos ferromagnesianos e possuem anomalias de $\mathrm{Eu}$ discretas. Nos diagramas de discriminação de granitóides arqueanos, situam-se nos campos de trondhjemitos e se alinham segundo o trend trondhjemítico. Suas características são compatíveis com as dos típicos granitóides arqueanos da série trondhjemítica (Barker 1979, Martin 1993);
(5) Comparações com os TTG da região de Xinguara revelaram que o Trondhjemito Mogno possui características geoquímicas transicionais entre o Complexo Tonalítico Caracol e o Trondhjemito Água Fria, enquanto que o Tonalito Mariazinha apresenta maiores semelhanças com o Complexo Tonalítico Caracol (Leite 2001);

(6) Os estudos detalhados efetuados no Trondhjemito Mogno e granitóides arqueanos associados mostram que as associações TTG do TGGRM são mais diversificadas do que era até então admitido e contribuíram para melhor compreensão dos TTG do TGGRM, reduzindo expressivamente as ocorrências da segunda geração de TTGs naquele terreno.

Agradecimentos Aos pesquisadores do Grupo de Pesquisa Petrologia de Granitóides (GPPG-IG-UFPA) pelo apoio nas diversas etapas deste trabalho; ao Instituto de Geociências (IG-UFPA) pelo suporte técnico; à CAPES pela concessão da bolsa de mestrado à primeira autora; ao CNPq por concessão de bolsas de doutorado (M. A. Oliveira e J. A. C. Almeida) e de produtividade em pesquisa (R. Dall'Agnol) e por apoio financeiro (Processo no 306348/2006-3). Aos revisores pelas críticas que levaram ao aperfeiçoamento do artigo. Este trabalho é uma contribuição para o INCT de Geociências da Amazônia (CNPq/MCT/FAPESPA - Processo no 573733/2008-2). 


\section{Referências}

Almeida J.A.C., Dall'Agnol, R., Oliveira, M.A., Macambira, M.J.B., Pimentel, M.M., Rämö, O.T., Guimarães, F.V., Leite, A.A.S., submitted . Zircon geochronology and geochemistry of the TTG suites of the Rio Maria granite-greenstone terrane: Implications for the growth of the Archean crust of Carajás Province, Brazil. Precam. Res.

Almeida J.A.C. 2010. Geologia, geoquímica, geocronologia e petrogênese das suites TTG e dos Leucogranitos arqueanos do Terreno Granito-Greenstone de Rio Maria, sudeste do Cráton Amazônico. Tese de Doutoramento, Instituto de Geociências, Universidade Federal do Pará, 208 p.

Almeida J.A.C., Dall'Agnol R., Oliveira D.C. 2006. Geologia, petrografia e geoquímica do Granito Anorogênico Bannach, Terreno Granito-Greenstone de Rio Maria, Pará. Rev. Bras. Geoc., 36:282-295.

Almeida J.A.C., Oliveira M.A., Dall'Agnol R., Althoff F.J., Borges R.M.K. 2008. Relatório de mapeamento geológico na escala 1:100.000 da Folha Marajoara (SB-22-z-c v). Programa Geobrasil, CPRM - Serviço Geológico do Brasil, 147 p.

Althoff F.J. 1996. Etude pétrologique et structurale des granitoïdes de Marajoara (Pará, Brésil): leur rôle dans l'évolution archéenne du craton Amazonien (2,7-3,2 Ga). Tese de Doutoramento, Université Henri Poincaré, Nancy I- France, 296 p.

Althoff F.J., Barbey P., Boullier A.M. 2000. 2.8-3.0 Ga plutonism and deformation in the SE Amazonian craton: the Archean granitoids of Marajoara (Carajás Mineral province, Brazil). Prec. Res., 104:187-206.

Barker F. 1979. Trondhjemites: definition, environment and hypotheses of origin. In: Barker F. (ed.) Trondhjemites, dacites and related rocks. Amsterdam, Elsevier, p. 1-12.

Barker F. \& Arth J.G. 1976. Generation of trondhjemitic-tonalitic liquids and Archaean bimodal trondhjemite-basalt suites. Geology, 4:596-600.

Bowden P., Batchelor R.A., Chapell B.W., Didier J., Lameyre J. 1984. Petrological, geochemical and source criteria for the classification of granitic rocks: a discussion. Earth Planet. Sci. Let., 35:1-11.

Condie K.C. 2005. TTGs and adakites: are they both slab melts? Lithos, 80:33-44.

Cordeiro A.A.C. \& Saueressig R. 1980. Serra das Andorinhas: geologia e principais ocorrências de ouro. In: SBG, Cong. Bras. Geol. 31, Camboriú, Resumos das comunicações, p. 344.

Dall'Agnol R., Oliveira M.A., Almeida J.A.C., Althoff F.J., Leite A.A.S., Oliveira D.C., Barros C.E.M. 2006. Archean and paleoproterozoic granitoids of the Carajás Metallogenetic Province, eastern Amazonian craton. In: Dall'Agnol R., Rosa-Costa L.T., Klein E.L. (eds.) Symposium on magmatism, crustal evolution, and metallogenesis of the Amazonian craton. Abstracts volume and field trips guide, Belém, PRONEX-UFPA/SBG-NO, 99-150.

Dall'Agnol R., Teixeira N.P., Rämo O.T., Moura C.A.V., Macambira M.J.B., Oliveira D.C. 2005. Petrogenesis of the Paleoproterozoic rapakivi A-type granites of the Archean Carajás metallogenic province, Brazil. Lithos, 80:101-129.

DOCEGEO. 1988. Revisão litoestratigráfica da Província Mineral de Carajás. In: SBG, Cong. Bras. Geol., 35. Belém, p.11-54.

Duarte K.D. 1992. Geologia e geoquímica do Granito Mata Surrão (SW de Rio Maria-Pa): um exemplo de granito "stricto sensu” Arqueano. Dissertação de Mestrado, Centro de Geociências, Universidade Federal do Pará, 217 p.

Halla J., Hunen J., Heilimo E., Hölttä P. 2009. Geochemical and numerical constraints on Neoarchean plate tectonics. Prec. Res., 179:155-162.

Hanson G.N. 1978. The application of trace elements in the petrogenesis of igneous rocks of granitic composition. Earth Planet. Sc. Let., 38:26-43.

Harker A. 1965. The natural history of igneous rocks. New York, Macmillan, $384 \mathrm{p}$.

Huhn S.R.B., Santos A.B.S., Amaral A.F., Ledsham E.J., Gouveia J.L., Martins L.B.P., Montalvão R.M.G., Costa V.G. 1988. O terreno granito-greenstone da região de Rio Maria - Sul do Pará. In: SBG, Congr. Bras.Geol. 35. Belém, Anais, 3:1438-1453.

Irvine T.N. \& Baragar W.R.A. 1971. A guide to the chemical classification of the common volcanic rocks. Can. J. Earth Sci., 8:523-547.

Jahn B.M., Glikson A.Y., Peuca J.J., Hickman A.H. 1981. REE geochemistry and isotopic data of Archean silicic volcanics and granitoids from Pilbara Block, Western Australia: implication for the early crustal evolution. Geochim. Cosmoch. Acta, 45:1633-1652.

Lameyre J. \& Bowden P. 1982. Plutonic rock type series: discrimination of various granitoid series and related rocks. $J$. Volcanol. Geoth. Res., 14:169-186.

Leite A.A.S. 2001. Geoquímica, petrogênese e evolução estrutural dos granitóides arqueanos da região de Xinguara, SE do Cráton Amazônico. Tese de Doutoramento, Centro de Geociências, Universidade Federal do Pará, 330 p.

Leite A.A.S., Dall'Agnol R., Macambira M.J.B., Althoff F.J. 2004. Geologia e geocronologia dos granitóides arqueanos da região de Xinguara (PA) e suas implicações na evolução do Terreno Granito-Greenstone de Rio Maria. Rev. Bras. Geoc., 34:447-458.

Leite A.A.S., Dall'Agnol R., Althoff F.J. 1999. Geoquímica e aspectos petrogenéticos do granito Xinguara, Terreno GranitoGreenstone de Rio Maria - Cráton Amazônico. Rev. Bras. Geoc., 23:429-436.

Le Maitre R.W. 2002. A classification of igneous rocks and glossary of terms. 2nd edition, London, $193 \mathrm{p}$.

Macambira M.J.B. 1992. Chronologie U/Pb, Rb/Sr, K/Ar et croissance de la croûte continentale dans L'Amazonie du sud-est; exemple de la région de Rio Maria, Province de Carajas, Brésil. Tese de Doutoramento, Montpellier, Université Montpellier II-France, $212 \mathrm{p}$.

Macambira M.J.B., Costa J.B.S., Althoff F.J., Lafon J.M., Melo J.C.V., Santos A. 2000. New geochronological data for the Rio Maria TTG terrane; implications for the time contraints of the crustal formation of the Carajás province, Brazil. In: SBG, International Geological Congress, 31st, Rio de Janeiro, CD-ROM.

Macambira M.J.B. \& Lafon J.M. 1995. Geocronologia da Província Mineral de Carajás; Síntese dos dados e novos desafios. Boletim do Museu Paraense Emílio Goeldi, Série Ciências da Terra, Belém, 7:263-287.

Macambira M.J.B. \& Lancelot J. 1996. Time constraints for the formation of the Archean Rio Maria crust, southeastern Amazonian Craton, Brazil. Internat. Geol. ver, 38:1134-1142. 
Martin H. 1994. The Archean grey gneisses and the gneisses of continental crust. In: Condie K.C. (ed.) Archean crustal evolution. Elsevier, Amsterdam, Developments in Precambrian Geology, 11:205-259.

Martin H., Chauvel C., Jahn B.M. 1983. Major and trace element geochemistry and crustal evolution of Archaean granodioritic rocks from eastern Finland. Prec. Res., 21:159-180.

Martin H. 1987. Petrogenesis of Archaean trondhjemites, tonalites and granodiorites from eastern Finland: major and trace element geochemistry. J. Petrol., 28:921-953.

Medeiros H. \& Dall'Agnol R. 1988. Petrologia da porção leste do Batólito Granodiorítico Rio Maria, sudeste do Pará. In: SBG, Congr. Brasileiro Geol., 35, Belém, Anais, 3:1488-1499.

Nakamura N. 1974. Determination of REE, Ba, Fe, Mg, Na and $\mathrm{K}$ in carbonaceous and ordinary chondrites. Geochim. Cosmochim. Acta, 38:757-775.

Neves A.P. \& Vale A.G. 1999. Redenção: folha SC.22- X-A. Estados do Pará e Tocantins, escala 1:250.000. Brasília: DNPM/ CPRM. Programa Levantamentos Geológicos Básicos do Brasil (PLGB), CD-Rom.

Nockolds S.R. \& Aleen R. 1953. The geochemistry of some igneous rock series, Part I. Geochem. Cosmochim. Acta, 4:105-142.

O'Connor J.T. 1965. A classification for quartz-rich igneous rocks based on feldspar ratios. US Geological Survey Profissional Papers, 525B:79-84.

Oliveira D. C. 2001. Geologia, geoquímica e petrologia magnética do granito paleoproterozóico Redenção, SE do Cráton Amazônico. Dissertação de Mestrado, Centro de Geociências, Universidade Federal do Pará, 207 p.

Oliveira D. C. 2006. Modelos de evolução e colocação dos granitos paleoproterozóicos da Suite Jamon, SE do Cráton Amazônico. Tese Doutoramento, Centro de Geociências, Universidade Federal do Pará,171p.

Oliveira M.A., Dall'Agnol R., Althoff F.J. 2006. Petrografia e geoquímica do Granodiorito Rio Maria da região de Bannach e comparações com as demais ocorrências no terreno Granito-Greenstone de Rio Maria-Pará. Rev.Bras. Geoc., 36:313-326.

Oliveira M.A., Dall'Agnol R., Althoff F.J., Leite A.A.S. 2009. Mesoarchean sanukitoid rocks of the Rio Maria GraniteGreenstone Terrane, Amazonian craton, Brazil. J. South Am. Earth Sci.. 27: 146-160.

Peccerillo A. \& Taylor S.R. 1976. Geochemistry of Eocene calcalkaline volcanic rocks from the Kastamoru area, Northern Turkey. Contr. Mineral. Petrol., 58:63-81.

Pimentel M.M. \& Machado N. 1994. Geocronologia U-Pb dos Terrenos granito-greenstone de Rio Maria, Pará. In: SBG, Cong. Bras. Geol., 38, Camboriú, Boletim de Resumos Expandidos, p. 390-391.

Rolando A.P. \& Macambira M.J.B. 2002. Geocronologia dos granitóides arqueanos da região da Serra do Inajá, novas evidências sobre a formação da crosta continental no sudeste do Cráton Amazônico, SSE Pará. In: SBG, Cong. Bras. Geol., 41, João Pessoa, Anais, p. 525.

Rolando A.P. \& Macambira M.J.B. 2003. Archean crust formation in Inajá range area, SSE of Amazonian Craton, Brazil, basead on zircon ages and $\mathrm{Nd}$ isotopes. In: South American Symposium on Isotope Geology, 4, Salvador.o, Expanded Abstracts, CD-ROM.

Santos J.O.S. 2003. Geotectônica do Escudo das Guianas e Bra-
sil-Central. In: Bizzi L.A., Schobbenhaus C., Vidotti R.M., Gonçalves J.H. (ed.) Geologia, tectônica e recursos minerais do Brasil: texto, mapas e SIG. Brasília: CPRM- Serviço Geológico do Brasil, p. 169-226.

Santos J.O.S., Hartmann L.A., Gaudette H.E., Groves D.I., McNaughton N.J., Fletcher I.R. 2000. A new understanding of the Provinces of the Amazon Craton based on integration of field and U-Pb and Sm-Nd geochronology. Gond. Res., 3:453-488.

Santos A \& Pena Filho J.I.C. 2000. Programa de levantamentos geológicos básicos do Brasil, Região de Xinguara, folha Xinguara (SB-22-Z-C), Estado do Pará. Texto explicativo, Brasília, DNPM/CPRM, 120p.

Shand S.J. 1950. Eruptive rocks their genesis, composition, classification and their relation to ore deposit. 4ed., London, Thomas Murby and Co., 488p.

Silva Jr. R.O., Dall'Agnol R., Oliveira E.P. 1999. Geologia, petrografia e geoquímica dos diques proterozóicos da região de Rio Maria, sudeste do Pará. Geochim. Brasiliensis, 13:163-181.

Souza Z.S. 1994. Geologia e petrogênese do "Greenstone Belt" Identidade: implicações sobre a evolução geodinâmica do terreno granito-"greenstone" de Rio Maria, SE do Pará. Tese de Doutoramento, Centro de Geociências, Universidade Federal do Pará, v- 1 e 2, 624 p.

Souza Z.S., Potrel H., Lafon J.M., Althoff F.J., Pimentel M.M., Dall'Agnol R., Oliveira C.G. 2001. Nd, Pb and Sr isotopes of the Identidade Belt, an Archaean greenstone belt of the Rio Maria region (Carajas Province, Brazil): implications for the Archaean geodynamic evolution of the Amazonian Craton. Prec. Res., 109:293-315.

Souza Z.S., Dall'Agnol, R., Oliveira C.G.; Huhn S.R.B. 1997. Geochemistry and petrogenesis of metavolcanic rocks from Archean greenstone belts: Rio Maria region (Southeast Pará, Brazil). Rev. Bras. Geoc., 27:169-180.

Streckeisen A.L. 1976. To each plutonic rock its proper name. Earth Sci. Rev., 12:1-33.

Tassinari C.C.G., Hirata W.K., Kawashita K. 1988. Geology of the Serra dos Carajás, Pará, Brazil, In: International Symposium on Archean and early Proterozoic Geologic Evolution anda Metallogenesis-ISAP. Salvador. Anais Rev. Bras. Geoc., 12:263-7.

Tassinari C.C.G. \& Macambira M.J.B., 2004. Evolução tectônica do Cráton Amazônico. In: Mantesso-Neto V., Bartorelli A., Carneiro C.D.R., Brito Neves B.B. de. (org.) Geologia do Continente Sul Americano: Evolução da obra de F.F.M. de Almeida. Beca, São Paulo, p. 471-486.

Vance J.A. 1969. On synneusis. Contrib. Mineral. Petrol., 24:7-29. Vasquez L.V., Rosa-Costa L.R., Silva C.G., Ricci P.F., Barbosa J.O., Klein E.L., Lopes E.S., Macambira E.B., Chaves C.L., Carvalho J.M., Oliveira J.G., Anjos G.C., Silva H.R. 2008. Geologia e Recursos Minerais do Estado do Pará: Sistema de Informações Geográficas - SIG: texto explicativo dos mapas Geológico e Tectônico e de Recursos Minerais do Estado do Pará. Organizadores, Vasquez M.L., Rosa-Costa L.T. Escala 1:1.000.000. Belém: CPRM.

Wedepohl K.H. 1970. Rubidium, Handbook of geochemistry. Berlin, Springer-Verlag, p. 37-B - 37-N.

Manuscrito ID 14741 Submetido em 08 de julho de 2009 Aceito em 01 de junho de 2010 